\title{
Saberes e uso da flora madeireira por especialistas populares do agreste de Sergipe
}

\author{
Juliano Silva Lima ${ }^{1}$, Débora Moreira de Oliveira ${ }^{2}$, José Elvino do Nascimento Júnior ${ }^{3}$, Renata Silva-Mann ${ }^{4}$ \\ \& Laura Jane Gomes ${ }^{5 *}$
}

${ }^{1}$ Núcleo de Pós-graduação em Agroecossistemas, ${ }^{2}$ Núcleo de Pós-graduação em Desenvolvimento e Meio Ambiente, ${ }^{4}$ Departamento de Engenharia Agronômica e ${ }^{5}$ Departamento de Ciências Florestais. Universidade Federal de Sergipe, Avenida Marechal Rondon, s/n, 49100-000, São Cristóvão, Sergipe, Brasil.

${ }^{3}$ Departamento de Botânica, Instituto de Biociência da Universidade de São Paulo, 05508-090, São Paulo, SP, Brasil.

\begin{abstract}
Resumo - Este trabalho teve como objetivo analisar o conhecimento da flora madeireira por especialistas em quatro comunidades rurais da região agreste de Sergipe. A coleta de dados ocorreu por meio da utilização de entrevistas semiestruturadas, turnê-guiada e coleta de plantas para registro botânico. As espécies madeireiras foram classificadas em quatro categorias, de acordo com o uso atribuído pelos 31 especialistas entrevistados: combustível, construção, tecnológico e outros. Foram identificadas 126 espécies distribuídas em 95 gêneros e 38 famílias, sendo $84 \%$ nativas da Mata Atlântica e $16 \%$ exóticas. Na categoria combustível, observou-se o maior número de citações, com 120 espécies, equivalente a $95 \%$ de todas as citações, distribuídas nas subcategorias: casa de farinha (76 espécies utilizadas), uso doméstico (48), e para comercialização (4). Na categoria construção, foram citadas 62 espécies; das quais, 49 se enquadraram na subcategoria construção civil, sendo utilizadas como peças, caibros e vigas, e 23 se enquadraram na subcategoria construção rural, sendo utilizadas em currais, cercas e cancelas. Para a categoria tecnologia, foram citadas 48 espécies, distribuídas em quatro subcategorias: utensílio (26), transporte (3), ferramenta (11) e outras tecnologias (16). Na categoria outros usos, duas espécies se enquadram em uso ornamental e uma em uso cultural. Constatou-se que os especialistas detêm um conhecimento amplo quanto ao uso de espécies madeireiras e utilizam critérios de seletividade, tais como qualidade, peso, odor, sazonalidade e aspectos religiosos.
\end{abstract}

Palavras-chave adicionais: comunidades rurais, conhecimento popular, recursos madeireiros.

\begin{abstract}
Knowledge and use of the timber flora by local experts from the agreste region of Sergipe) - This work presents a study about use and knowledge of the flora in forest fragments used by local experts from communities in the agreste region of Sergipe. Data was collected using semi-structured interviews, performance-guided tours, and by harvesting plants for the floristic inventory. The timber species were classified into four categories according to the use given by the 31 local experts interviewed: fuel, wood, construction and other. A total of 126 species, 95 genera and 38 families were identified; $84 \%$ of them are native to the Atlantic Forest and $16 \%$ exotic. The fuel category presented the largest number of records, with 120 species, representing $95 \%$ of all records, divided into subcategories: flour (with 76 species used), household use (48), and commercial (4). Under construction, 62 species were cited; amongst which, 49 belong to the subcategory building construction, being used as parts, rafters and joists, and 23 species fit in the subcategory rural construction, being used in corrals or pens, fences and gates. Under technology, 48 species were cited, divided into four subcategories: utensils (26), transport (3), tools (11) and other technologies (16). In the category 'other uses', two species were used as ornamentals and one in cultural use. The experts provided a broad knowledge about the use of timber species and use selective criteria, such as quality, weight, smell, seasonality and religious aspects.
\end{abstract}

Additional Key words: local knowledge, rural communities, timber resources.

A utilização dos recursos naturais, associada às exigências culturais e biológicas da sociedade humana, vem intensificando a necessidade de incorporar conhecimentos básicos sobre os diversos ecossistemas e geração de tecnologias capazes de promover resultados efetivos no manejo da flora (Souza 2002). Isso porque, ao conhecer as espécies de um ecossistema, pode-se prever melhor os mecanismos capazes de conservar grupos de vegetais em risco de extinção a fim de estabelecer estratégias de conservação e manejo dos seus usos (Fraga 2000).

Com a intensificação da degradação da maioria das

\footnotetext{
*Autora para correspondência: laurabuturi@gmail.com

Editor responsável: Ulysses Paulino de Albuquerque

Recebido: 19 maio 2011; aceito: 13 jul. 2011.
}

formações vegetais brasileiras, estudos etnobotânicos têm recebido maior atenção dada a sua importante contribuição em programas de recuperação de áreas degradadas, avaliação de impactos ambientais e até mesmo em planos de manejo de fragmentos florestais e reflorestamentos (Caiafa 2002). Em Sergipe, assim como em outros estados do Brasil, a intensificação do uso dos recursos naturais e a consequente fragmentação florestal tem sido um processo observado com frequência, decorrente da substituição de parte das florestas por pastagem ou agricultura e da retirada seletiva de produtos florestais madeireiros (Aguiar-Netto 2006).

A madeira é o principal produto obtido de plantas lenhosas e também aquela cuja extração é mais danosa às 
populações vegetais, já que na maioria das vezes toda a planta é retirada para a obtenção do recurso. Além do uso comercial em larga escala, o uso de espécies nativas lenhosas pode ser empregado para suprir as necessidades das populações locais, tais como: fonte de combustível para aquecimento e cocção de alimentos, construção de casas, delimitação de terrenos por meio de cercas, confecção de ferramentas de trabalho, entre outros (Ramos et al. 2010).

$\mathrm{Na}$ Região Nordeste, o uso madeireiro pelas comunidades que vivem no entorno de fragmentos florestais é muito comum. Não raro, pode-se observar nas casas a presença de chaminés, fogões à lenha, feixes de lenhas, além da própria construção de casas ou cercados oriundos de espécies arbóreas e arbustivas da região. Os trabalhos existentes na literatura que dizem respeito ao consumo de lenha ou ao uso do recurso madeireiro para construção civil e rural geralmente se referem aos consumidores de maior porte, ou seja, aqueles que promovem desmatamentos perceptíveis e consomem uma quantidade elevada dos recursos florestais (Silva \& Andrade 2005). No entanto, é importante que se tenha conhecimento da retirada seletiva das espécies lenhosas pelas comunidades que vivem no entorno dos fragmentos florestais, pois mesmo retirando matéria-prima apenas para suprir as necessidades de autoconsumo, podem causar impactos significativos às comunidades vegetais. Neste sentido, torna-se necessário o conhecimento da demanda de recursos madeireiros dessas populações e os usos empregados, para que se possa garantir de forma efetiva o uso sustentável dos recursos florestais.

Apesar de alguns estudos sobre a flora do agreste sergipano terem sido realizados devido à presença do Parque Nacional Serra de Itabaiana e de importantes nascentes de rios (Ferreira et al. 2006; Gomes \& Maroti 2006; Lima et al. 2009), ainda pouco se conhece sobre a relação que as populações locais têm com os remanescentes vegetais. Dessa forma, estudos que visem conhecer as espécies vegetais madeireiras e a relação desses recursos com as comunidades locais são ferramentas importantes no sentido de contribuir para o manejo e conservação das espécies que sofrem maior pressão antrópica. Diante desse contexto, o objetivo desse estudo foi realizar o levantamento etnobotânico da flora madeireira em quatro comunidades do agreste sergipano, visando à identificação das espécies, a investigação dos padrões de uso, a qualidade dos recursos madeireiros e o manejo das espécies botânicas por parte dos especialistas populares na região.

\section{Material e Métodos}

Área de estudo. Foram selecionadas para o estudo quatro comunidades rurais estabelecidas às margens do rio Poxim-Açu: Pedrinhas (1049'464''S, 37¹9'002'W), Caroba (1049'983"S, 37²2'584"W), Cajueiro (1050'314”S, $\left.37^{\circ} 23^{\prime} 747^{\prime \prime} \mathrm{W}\right)$ e Ladeira (1050'069'S, 37¹9'102'W), formadas por vilas rurais, com grandes áreas de pastagens e monocultivo de cana-de-açúcar e por diversos sítios pequenos destinados à agricultura familiar. A distância entre as comunidades Pedrinhas e Ladeira é 1,06 km, entre ladeira e Caroba 8,6 km, entre Caroba e Cajueiro $2 \mathrm{~km}$, totalizando $11,66 \mathrm{~km}$ entre as comunidades mais distantes, Pedrinhas e Cajueiro (Figura 1).

As comunidades Pedrinhas (2.150 habitantes) e Caroba (450 habitantes) estão localizadas no município de Areia Branca e a distância entre elas e a sede do município está em torno de $5 \mathrm{~km}$. Ladeira (700 habitantes) e Cajueiro (550 habitantes) estão localizadas no município de Itaporanga d'Ajuda e a distância entre elas e a sede do município está em torno de $40 \mathrm{~km}$. Todas contam com infraestrutura básica, como escolas de ensino fundamental, pequenos estabelecimentos comerciais, como mercadinhos

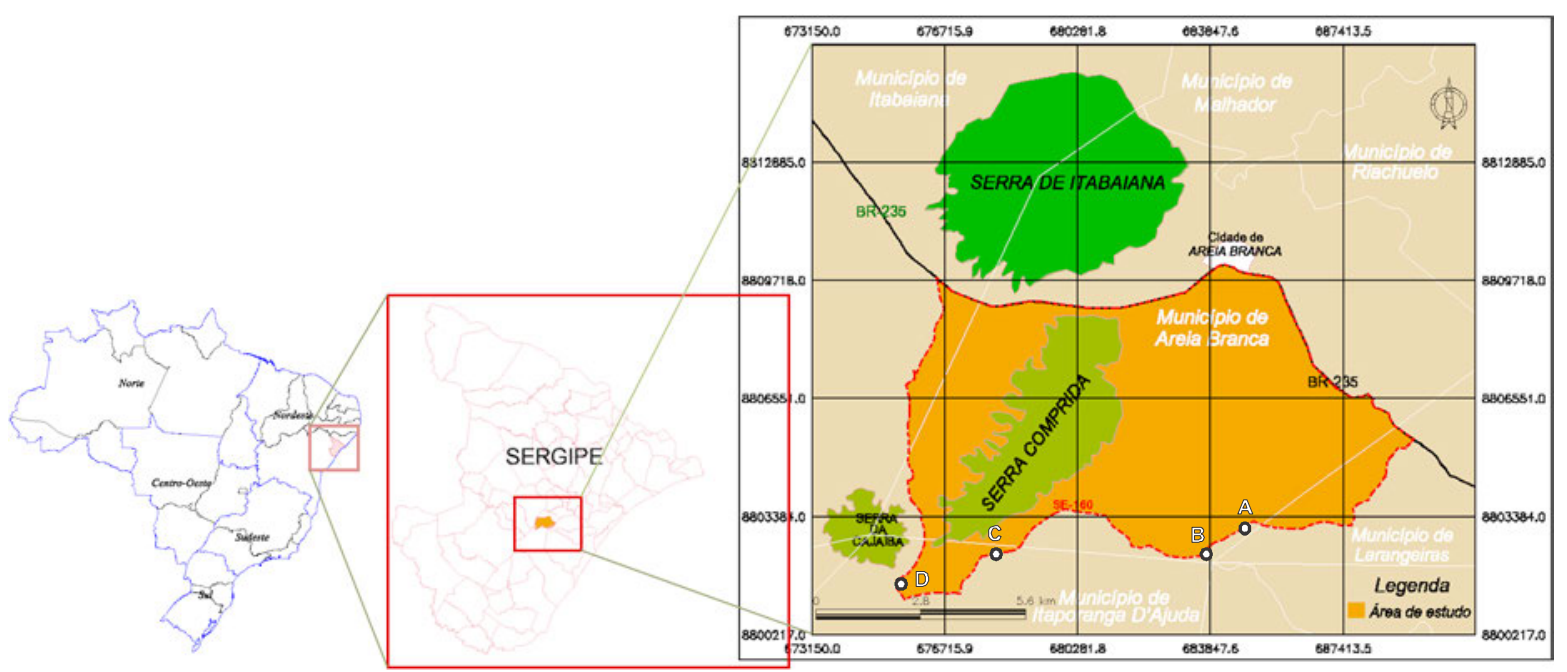

Figura 1. Localização das comunidades rurais estudadas no entorno do Parque Nacional Serra de Itabaiana. A- Comunidade Pedrinhas; BComunidade Ladeira; C- Comunidade Caroba; D- Comunidade Cajueiro. 
e bares. A maioria das casas dispõe de fossa ou sumidouro. O acesso a água é oriundo de um chafariz público, poços e cacimbas (Gomes \& Maroti, 2006).

Nas áreas próximas ao rio Poxim-Açu, delimitada pelo município de Itaporanga d'Ajuda existem diversas áreas destinadas à agricultura familiar, em especial a pequenas produções de mandioca, feijão, milho, maracujá, amendoim, batata e coco (IBGE 2012). Já na região de Areia Branca, observou-se o desenvolvimento da economia local, baseado no monocultivo de pastagens e cana-de-açúcar, atividade empregadora de mão-de-obra de forma temporária durante as fases de plantio e corte.

As comunidades estudadas estão localizadas no entorno do Parque Nacional Serra de Itabaiana que foi criado por estar localizado em uma região de contato da Mata Atlântica com o Semiárido, através do agreste, estabelecendo na região uma zona de transição, na qual coexistem espécies da fauna e flora de ambos os ecossistemas, distribuídas por entre formações vegetais fechadas e abertas. As áreas fechadas são constituídas por vegetação arbórea secundária, localizadas principalmente nas encostas, acompanhando os riachos que recortam as serras (Vicente et al. 1997; Vicente 1999). Dantas et al. (2010) descreve as áreas de matas dessa região com a permanência da maioria de suas folhas durante todo o ano, conferindolhe aspecto semelhante à Mata Atlântica de tabuleiros (Floresta Ombrófila Densa de Terras Baixas), porém com a frequência das formas de vida vegetais características da Floresta Estacional Semidecidual Submontana, onde a abundância de epífitos é menor que na Floresta Ombrófila Densa.

Os especialistas indicaram ter conhecimento de três hábitats distintos para coleta de recursos madeireiros: floresta úmida, tabuleiro (areia branca) e áreas antropogênicas, com plantações agrícolas e plantas exóticas (Carvalho \& Vilar 2005).

Coleta e análise dos dados. A pesquisa exploratória teve como objetivo a observação in loco das características estruturais e ambientais das comunidades (Macedo 2006), a aproximação com os moradores e a investigação sobre a existência de pessoas na região que apresentassem algum tipo de conhecimento popular botânico (especialistas), sendo selecionadas através do método de "bola-de-neve" (Baley 1994). Os dados foram coletados a partir de uma amostra não probabilística do tipo intencional por meio do qual os especialistas (marceneiros, artesãos, carpinteiro, mateiros, etc.) foram selecionados de acordo com informações de membros da comunidade (Galeano 2000; Spata 2005).

A coleta de dados se deu por meio de entrevistas semiestruturadas (Combessie 2004) e turnê guiada durante o período de março de 2009 a fevereiro de 2010 , na qual o roteiro de entrevistas contemplou perguntas que permitiram conhecer o perfil dos especialistas, além das espécies madeireiras que são mais utilizadas, e de que modo são utilizadas (Ramos et al. 2010). Os dados foram categorizados em usos mais e menos importantes, além de identificar possíveis relações etnobiológicas entre o uso dessas plantas com o contexto cultural (Aguillar \& Condit 2001). As definições de usos madeireiros utilizadas neste trabalho foram delimitadas como categorizações éticas a partir de dados êmicos amplos (medicinal, madeireiro, alimentício, místico-religioso) coletados nas quatro comunidades rurais.

Foram entrevistados 31 especialistas locais: 14 residentes em Pedrinhas, sete em Ladeira, cinco em Caroba e cinco em Cajueiro, sendo 18 do sexo masculino e 13 do feminino, com idades entre 45 e 92 anos, e com tempo de residência na comunidade de no mínimo 30 anos. A maioria dos entrevistados (55\%) é analfabeta, sendo que 13 especialistas possuem formação até a $4^{\mathrm{a}}$ série $(42 \%)$ e apenas um concluiu o ensino médio (3\%). As ocupações dos especialistas se distribuíram em lavrador, doméstica, pedreiro, carpinteiro e comerciante. Todos os especialistas entrevistados concordaram em participar da pesquisa e firmaram compromisso por meio de assinatura de um termo de consentimento livre e esclarecido.

A coleta botânica foi realizada durante caminhadas aleatórias com os especialistas nos locais onde eram coletados os recursos vegetais (Begossi et al. 1993). Durante as turnês-guiadas (Albuquerque et al. 2010), informações sobre todas as plantas coletadas foram anotadas em fichas de campo - ambiente, nome vernacular, características, hábito - além de dados complementares sobre conhecimento popular acerca do uso das espécies madeireiras nessa região (Ramos et al. 2010). O material botânico coletado foi desidratado em estufa, sendo posteriormente encaminhado ao Herbário da Universidade Federal de Sergipe (UFS) e identificado mediante comparações com exsicatas, envio a especialistas e consultas bibliográficas (Souza \& Lorenzi 2005). Todas as espécies citadas foram coletadas para a identificação, porém só foram incorporados no herbário ASE os espécimes em bom estado de conservação ou com ramos reprodutivos. O sistema de classificação botânica utilizado foi o proposto pelo Angiosperm Phylogeny Group (APG III 2009).

Todas as plantas citadas nas quatro comunidades foram classificadas quanto ao seu local de origem e a(s) categoria(s) de uso. A determinação da origem foi obtida por consultas às obras de Souza \& Lorenzi (2005) e ao site oficial do Missouri Botanical Garden (TROPICOS 2010), sendo considerada planta nativa aquelas de áreas do domínio da Mata Atlântica e planta exótica aquelas oriundas de outras áreas.

As informações foram tabuladas numa matriz contendo os seguintes campos: família, nome científico, nome local, origem, número de citações, usos, indicações de uso e qualidade das espécies de uso madeireiro. Todos os usos foram padronizados e adaptados em categorias de uso madeireiro, de acordo com a proposta de Ramos et al. (2010): 1- Combustível - espécies destinadas à queima, para liberar 
energia através da produção de calor. Seu destino pode ser para cocção e defumação de alimentos, aquecimento de água ou de ambientes; 2- Construção - espécies que fazem parte de estruturas para fins de delimitação territorial, moradia ou abrigo de animais e objetos; 3- Tecnológico - espécies que sofrem manipulação da matéria prima original, mas que não é utilizada para delimitação de espaços; 4- Outros: espécies destinadas às fogueiras juninas e para ornamentação.

Para a classificação da qualidade dos recursos madeireiros, foi solicitado aos informantes, no momento das entrevistas e nas coletas botânicas, que dessem uma nota de 1 a 4 para cada recurso citado e coletado. O padrão de classificação de qualidade desses recursos se estabeleceu a partir da média de valores dada por todos os especialistas, no qual foram padronizados os seguintes valores: $0-1=$ ruim, $1,1-2,0=$ média, $2,1-3,0=$ boa, $3,1-4=$ muito boa.

Tendo em vista que a diversidade envolve tanto a riqueza de espécies de determinado local, como a forma pela qual elas se encontram distribuídas (abundância ou equitabilidade), foi calculado o índice de diversidade de Shannon-Weaver, que permite verificar o quanto de diversidade local é usada pela população, e o de equabilidade de Pielou, para se verificar a existência ou não de dominância no uso de algumas espécies (Prance et al. 1987; Begossi 1996).

Sob o aspecto qualitativo registrou-se alguns diálogos específicos que foram caracterizados como "memes", os quais formaram partes de informações contextualizadas (Marques 2002).

\section{Resultados E Discussão}

Foram listadas 126 espécies distribuídas em 95 gêneros e 38 famílias (Apêndice). Das espécies identificadas, constatou-se que $65 \%$ são coletadas em fragmentos de florestas úmidas, 20\% em áreas de tabuleiros (areia branca) e 15\% em áreas antropogênicas. A maior parte das espécies citadas nas entrevistas (84\%) são nativas da região; apenas $16 \%$ são exóticas. A alta porcentagem de espécies nativas citadas como úteis, pode estar relacionada com a alta diversidade dos fragmentos florestais onde as comunidades rurais estão inseridas. Segundo Hanazaki et al. (2000), a diversidade de conhecimento e usos das plantas pode ser afetada pela sua disponibilidade, podendo ser gradualmente aumentada ou diminuída à medida que essa biodiversidade é mantida ou extinta.

A família com maior número de espécies citadas foi Leguminosae, com 26 espécies, o que corresponde a $21 \%$ daquelas citadas neste estudo. As outras famílias com maior número de espécies citadas foram Myrtaceae (13 espécies) e Anacardiaceae (7). Botrel et al. (2006), em Minas Gerais, e Lima et al. (2000), no Paraná, também encontraram em Leguminosae o maior número de espécies citadas pelas comunidades pesquisadas, sendo a maioria delas utilizadas para fins medicinais e madeireiros. Já em outra pesquisa, realizada na Mata Atlântica da região do Rio de Janeiro, Fonseca-Kruel \& Peixoto (2004) observou que a família Myrtaceae foi a mais representativa.

O índice da diversidade de Shannon-Weaver para uso das espécies foi de $H^{\prime}=3,9$. Esse valor pode ser considerado alto quando comparado com outros trabalhos etnobotânicos realizados com comunidades localizadas próximas à região de Mata Atlântica (Figueiredo et al. 1993; Begossi et al. 1993; Rossato et al. 1999; Lima et al. 2000; Hanazaki et al. 2000; Fonseca-Kruel \& Peixoto 2004). Para Begossi (1996) índices de diversidade alta sugerem que a população utiliza uma grande parcela da diversidade local e espera-se que quanto maior a diversidade florística local, maior a diversidade das espécies usadas.

Já para análise do índice de equabilidade de Pielou, o resultado foi $\mathrm{J}=0,73$, sugerindo dessa forma que a população estudada conhece e utiliza a maior parte das espécies disponíveis no ambiente e que não há um predomínio no uso de apenas algumas espécies (Botrel et al. 2006). O valor do índice de Shanon-Weaver e o de Pileou corroboraram a hipótese de que as comunidades afastadas dos centros urbanos locais e localizadas em região de alta diversidade biológica possuem elevado conhecimento etnobotânico (Begossi et al. 2002).

A seguir, será discutido o conhecimento das plantas madeireiras distribuídas nas categorias de uso registradas nesse trabalho: Combustível, Construção, Tecnologia e Outros usos.

Combustível. Para esta categoria de uso observou-se o maior número de citações, com 120 espécies, o equivalente a $95 \%$ de todas as citações. Destas, 106 são plantas nativas da região de Mata Atlântica. Com base neste resultado, pode-se inferir sobre a grande importância das espécies utilizadas para lenha no cotidiano das comunidades rurais do agreste sergipano. A relação existente entre o uso da lenha nessas comunidades é muito forte nas residências, devido ao alto custo do gás de cozinha, assim como nas casas de farinha, onde ocorre o processo de beneficiamento da mandioca (Gomes \& Maroti 2006). Dentre os trabalhos que tratam das referidas categorias, a categoria combustível também foi a mais expressiva nos trabalhos de Lima et al. (2000), Fonseca-Kruel \& Peixoto (2004) e Christo et al. (2006).

Para esta categoria, as plantas foram divididas em três subcategorias relacionadas com o uso de lenha nos diversos espaços, assim relacionadas: 76 espécies citadas como combustíveis para a casa de farinha, 48 espécies para uso doméstico e quatro espécies exportadas das comunidades que são utilizadas em olarias e padarias das áreas urbanas da região.

As espécies com maior número de citações como combustível foram: murici-da-mata (Byrsonima sericea DC.; 31 citações), candeia [Eremanthus incanus (Less). Less; 28], araçá-goiaba (Psidium guianense Pers.; 27), pau-pombo 
(Tapirira guianensis Aubl.; 27) e cajueiro (Anacardium ocidentale L.; 21).

O número alto de espécies de uso combustível está provavelmente relacionado à facilidade com que algumas espécies são encontradas na região. Como exemplo, a espécie $B$. sericea, que foi citada por todos os especialistas, destacando-se pela facilidade de acesso e seu alto poder de queima. Essas relações se devem provavelmente ao fato de que o conhecimento a respeito dessas espécies foi passado de geração para geração e algumas vezes a própria necessidade pode ter direcionado as pessoas a esse conhecimento empírico (Ramos et al. 2008).

Ainda que a princípio esses especialistas não apresentem claramente estratégias de manejo e escolha das espécies, observou-se a existência de uma relação intrínseca entre a qualidade da lenha (ruim, média, boa, muito boa) e o seu destino final (residências, casa de farinha e outras localidades). As lenhas consideradas boas ou médias são destinadas geralmente aos fornos das residências, já as lenhas identificadas localmente como de qualidade inferior são usadas nas casas de farinha. As espécies consideradas muito boas são vendidas separadamente aos donos de olarias e padarias das cidades de Itabaiana e Areia Branca, Sergipe. Convém ressaltar que a comercialização de espécies de lenha para fora da comunidade foi constatada no estudo de Gomes \& Maroti (2006).

Os critérios utilizados pelos especialistas para classificar as qualidades da lenha baseiam-se em alguns preceitos compartilhados culturalmente na região, tais como: quanto mais tempo a lenha manter a brasa acesa melhor ela será; as melhores lenhas são as secas tanto no verão quanto no inverno; e a lenha, para ser boa, não pode liberar um odor muito forte. Entretanto, neste estudo, mesmo algumas espécies citadas como ruins para uso como fonte energética, a exemplo da embaúba (Cecropia pachystachya Trécul), bula-cinza (Hirtella ciliata Mart. \& Zucc.) e sambaíba (Curatella americana L.), ainda são usadas como combustível por alguns especialistas que possuem menor poder aquisitivo, e utilizam a lenha como única forma de cocção dos alimentos. Conforme relatos identificados nas entrevistas: "Sendo pau seco, a gente queima tudo." e "Sambaíba, o povo não queima, mas porque diz que é santa; na falta de outra melhor, a gente queima também." $\mathrm{O}$ uso de lenha em diferentes comunidades locais está relacionado a diferentes fatores: para conferir melhor sabor ao alimento, para manter as tradições e, principalmente, para redução de gastos (Botrel et al. 2006; Kakudidi 2007).

Neste sentido, observa-se entre os especialistas do agreste sergipano, uma mesma lógica de uso do recurso energético, onde o fator financeiro é preponderante para os critérios de seletividade das espécies. No entanto, entre a maioria dos especialistas entrevistados observam-se indícios de estruturas meméticas de seletividade e restrição do uso de certas espécies lenhosas, baseada em preceitos culturais, fisiológicos e religiosos. Segundo Lévi-Strauss
(1987) e Sá e Silva et al. (2009), é comum que as comunidades locais estabeleçam formas de seleção e manejo das espécies florísticas, obedecendo atributos culturais e fisionômicos, como forma de manutenção das espécies úteis.

Uma das formas de seleção observadas nas áreas estudadas baseia-se na qualidade da lenha em relação a determinada estação do ano. No verão, a maioria das espécies consegue ser queimada devido à baixa retenção de umidade dessas plantas. Por outro lado, no inverno, a maioria das espécies permanece úmida e flácida, o que dificulta o processo de queima nos fogões à lenha. A embaúba, por exemplo, é bastante usada nos fornos da casa de farinha no verão (estação seca), mas no período de inverno deixa de ser usada devido à umidade que o caule dessa espécie absorve, dificultando assim o processo da queima.

Outra espécie que mantém característica semelhante à embaúba é a bula-cinza, que se caracteriza por produzir muita cinza no processo de queima, como o próprio nome vernacular indica. Essa espécie também só é usada pelos especialistas quando mesclada a outras plantas lenhosas, apenas na estação seca. Já a candeia e o pau-pombo são usados principalmente na estação chuvosa, já que permanecem menos úmidos. Conforme comentários detectados durante as turnês-guiadas: "A bula-cinza só faz cinza, fede, faz fumaça e não esquenta o fogo."; "A embaúba nem todo mundo gosta de queimar, porque é lenha fofa, não faz brasa, mas no verão tudo se queima."; "Candeia é uma das melhores, mas como tem pouca só se queima no inverno."

Essa seletividade, atribuídas pelos especialistas, voltada a diferenciar as lenhas que são usadas na estação seca e na estação chuvosa é decorrente provavelmente da diminuição gradativa do número de recursos lenhosos nessa região. Dessa forma, as comunidades locais da região do agreste sergipano criaram uma estratégia de manutenção dos estoques florísticos a partir da alternância de usos das espécies de plantas. Ou seja, mesmo uma espécie teoricamente sem afinidade para uso energético, como a embauba, é usada como lenha no período do verão, segundo os informantes, devido à sua alta incidência nessa região e às suas características fisiológicas. Ao adotarem essa estratégia, as comunidades locais diminuem a pressão antrópica voltada às espécies de plantas consideradas boas, com menor retenção de umidade, e consequentemente, no período chuvoso, essas lenhas melhores estarão disponíveis para o uso. A manutenção dessa seletividade a partir das características morfoclimáticas, provavelmente tenha sido uma das formas de manejo, mantidas ao longo do tempo, o que tem contribuído para a manutenção dos poucos fragmentos florísticos na região estudada.

Outra forma de seleção refere-se ao odor liberado na queima das lenhas. Geralmente as espécies que liberam odor forte ou fumaça escura são evitadas ou misturadas com 
outras lenhas e utilizadas preferencialmente nas casas de farinha. O que leva os especialistas a evitarem essas espécies de plantas pode estar relacionado a dois motivos principais: o odor forte da lenha pode modificar o sabor da comida e acredita-se que a fumaça escura e seu "mau cheiro" possam causar doenças. Conforme detectados nos comentários durante as entrevistas: "Angelim no pode queimar, porque é fedorenta e pode dar reumatismo. É um fedor que não tem quem suporte."; "Se queimar sapateiro a comida que tiver sendo feita perde, o gosto fica perdido, é mesmo que comer fumaça preta."; "Não se pode queimar sapateiro em casa, a fumaça dá doença na junta [articulação].".

Sobre a influência da fumaça na saúde, a literatura científica possui diversos relatos onde a fumaça gerada pela queima de madeira é causadora ou potencializadora de doenças, como no caso da Doença Pulmonar Obstrutiva Crônica (DPOC) (Yaksic et al. 2003; Godoy 2008; Moreira et al. 2008).

Essas atribuições relacionadas ao odor estão fortemente ligadas à ideia de que os "cheiros" expelidos pelas plantas podem curar ou causar doenças à medida que são agradáveis ou não. Essas partículas meméticas são comuns nessa região, onde se observa o uso de plantas para os rituais de cura a partir da defumação de cascas, folhas e flores. A fumaça e os odores liberados pelas plantas possuem diversos significados místicos e farmacológicos, entre os especialistas, que são frequentemente usados nos processos de curas de doenças e de encantamentos.

Entre os especialistas entrevistados, observam-se também indícios de seletividade e restrição do uso de certas espécies lenhosas baseadas em preceitos culturais, fisiológicos e religiosos. A influência do misticismo e da religiosidade dos especialistas dessa região pode contribuir para a preservação de várias espécies da flora local. A crença popular, por exemplo, tem um papel no controle do uso de algumas espécies, que apesar de serem citadas como boas para lenha são poupadas devido aos aspectos "mágicos" que a planta detém, a exemplo do cedro (Cedrela sp.), conforme o comentário a seguir: "O povo não gosta de queimar cedro porque é protegido pelos santos e quando queima deixa o cheiro na comida, só que não faz mal a ninguém." No estudo realizado por Botrel (2006), foi observado também relações místicas que influenciam diretamente no uso dos recursos lenhosos. A lenha da embaúba, na região de Ingaí, Minas Gerais, é considerada como ruim para queimar, pois é tradição dos mais velhos dessa região não queimar essa madeira para não trazer azar.

Espécies como a sucupira (Bowdichia virgilioides Kunth), biriba [Escweleira ovata (Cambess.) Miers], sapucaia (Casearia grandiflora Cambess.) e cedro (Cedrella sp.), que são destinadas geralmente à fabricação de móveis, portas e construção, também são evitadas para uso como forma de combustível, por serem consideradas de uso nobre. Além disso, essas espécies são consideradas "muito pesadas", e por isso, muitas vezes são dispensadas, já que, em geral, quem faz a coleta de lenha são as mulheres, que suportam, em condições normais, menos peso do que os homens.

Construção. Na categoria construção, foram citadas 62 espécies, o que equivale a $49 \%$ do total de espécies citadas. Das espécies nativas citadas, $55 \%$ são utilizadas nesta categoria e das exóticas, $35 \%$. Além disso, foram criadas duas subcategorias, que englobam as espécies usadas na construção civil (49 espécies) e na construção rural (23).

Das espécies indicadas para a subcategoria construção civil, a espécie mais citada foi a sucupira (Bowdichia virgilioides Kunth; 30 indicações), seguida pelo murici-da-mata (25), a biriba (24) e o cocão (Malpighiaceae sp.; 19). Nessa subcategoria, observa-se a presença de uma classificação êmica entre as espécies de plantas usadas na construção civil. Os especialistas classificam essas espécies em dois grupos distintos: (1) madeira do ar, aquelas que são usadas para construção de cumeeira, caibro e ripa e (2) madeira do chão, aquelas madeiras usadas para a construção de esteio, finco e vara.

Os critérios usados para classificação desses dois grupos baseiam-se na resistência da madeira. As espécies mais resistentes à "ação do tempo" são classificadas como "madeira-do-chão", como a sucupira, a biriba, a sapucaiacoco (Lecythis pisonis Cambess.) e pau-d'arco (Handroanthus sp. 1). Já as espécies menos resistente ao contato com a terra, são consideradas "madeiras-do-ar", a exemplo do miroró [Bauhinia cheilantha (Bong.) Steud.], o bumba-boi [Himatanthus bracteatus (A.DC.) Woodson], o ganhador [Pera glabrata (Schott) Poepp. ex Baill.] e a maçaranduba [Manilkara salzmannii (A.DC.) H.J.Lam.].

Além da madeira-do-chão e madeira-do-ar existem outras espécies agrupadas na construção civil, mas que são indicadas para a construção de portas e janelas. A jaqueira (Artocarpus heterophyllus Lam.) foi a mais citada para este uso, com 25 indicações, seguida da paraíba (Simarouba sp.) e do cedro (Cedrela sp.), com 14 indicações cada.

Na subcategoria construção rural, as 23 espécies citadas foram distribuídas em mais três categorias, a saber, construção de curral, cancela e cerca. Dentre as espécies mais utilizadas nessa subcategoria, destacam-se a biriba e o murici-da-mata, com 20 citações cada.

No que se refere às estratégias de critérios de escolha das plantas para fins de construção observa-se que a resistência, a beleza e o peso reduzido são os principais critérios para selecionar se a madeira é considerada boa ou ruim. Outro ponto evidenciado pelos especialistas referese à existência de um regime de corte ideal que deve ser 
respeitado. Segundo os entrevistados, o corte de espécies madeireiras deve ser feito durante a lua nova, para que a madeira não rache, ou não "dê" cupim: "A madeira só pode cortar na hora em que a lua esteja embaixo, na hora que ninguém não enxergue ela [Lua nova]."; "Tem que tirar na época quando a lua ta escura. Porque se tirar com a lua clara, a madeira bicha." Este fato pode ser fundamentado na concentração de certos compostos existentes nas plantas, que pode ser alterada de acordo com as condições do meio em que estas se encontram (Amorozo \& Gely 1988).

O uso do termo "madeira-de-lei” é muito comum entre os especialistas. Uma delas, a sucupira, foi indicada como uma das espécies mais exploradas em alguns fragmentos de mata, onde foram realizadas as coletas do material botânico. Uma espécie de origem exótica, a jaqueira, é também muito usada na região para construção de móveis, portas e janelas.

Além dos critérios de seleção acima, outras forma de coleta seletiva podem contribuir para a preservação de algumas espécies vegetais indicadas para essa finalidade. As madeiras de caules tortos ou difíceis de serem talhados são evitadas, bem como as plantas místicas, por medo de que possam dar má-sorte na casa. Conforme comentários na entrevista. "O marmeleiro é uma madeira boa, mas falam que é a morada do diabo, fazer qualquer parte com marmeleiro dá azar."

Diferente do elevado número de espécies nativas citadas para a categoria combustível, observou-se a formação de um novo padrão de tipo de uso de plantas madeireiras para a categoria construção, em que as espécies nativas vão aos poucos sendo substituídas por espécies exóticas. Isso pode ocorrer devido ao porte diferenciado entre as espécies, que são indicadas para diferentes finalidades. Isto é, espécies de uso para construção demandam maior tempo para alcançar o porte necessário. Desse modo, as nativas que possuíam o porte necessário para o seu uso na construção foram sendo exauridas na localidade, e por conseguinte, substituídas por espécies exóticas cultivadas geralmente nos quintais das propriedades.

O uso alternativo de lenha não nativa não é muito comum nas áreas rurais. Entretanto, para alguns moradores dessas comunidades, o uso como lenha de plantas exóticas oriundas dos quintais tem se tornado frequente. $\mathrm{O}$ uso principalmente de galhos de uma espécie de mangueira (Mangifera indica L.) e de cajueiro está se popularizando na comunidade devido às dificuldades de retirar lenha de espécies nativas oriundas de fragmentos de mata da região do rio Poxim-Açu, que em sua maioria estão em posse de grandes proprietários rurais.

Segundo relato dos especialistas, os proprietários desses fragmentos não permitem a retirada de lenha em suas terras, exceto quando se trata de pequenos feixes lenhosos de galhos secos. Outro fator que tem dificultado a coleta de espécies nativas na região tem sido a fiscalização ambiental em alguns trechos dessas comunidades. Como nota-se neste relato: "Quando os homem do IBAMA passa eles empata pegar lenha. O IBAMA fica passando pra ver se tem alguém que ta pegando lenha verde."

No entanto, mesmo com o uso de algumas espécies exóticas para lenha, a preferência pela espécies nativas ainda persiste. Quando questionado se o uso de lenha nas casas é maior ou menor do que antigamente os especialistas afirmaram que o uso da lenha tem sido igual, porém o que mudou foi a dificuldade em achar a lenha: "Antes aqui era tudo mato. Depois que venderam tudo, acabaram com meio mundo de mata." Neste sentido, a falta de condições financeiras para se usar fogão à lenha, a escassez de informação e de um plano de manejo nessas áreas fazem com que parte da população retire a lenha sem a permissão dos proprietários rurais ou sem a permissão do IBAMA.

Tecnologias. A categoria tecnologias obteve 48 espécies citadas, o que equivale a $38 \%$ do total. Destas, 36 são nativas (34\% do total de nativas) e 12 são exóticas ( $60 \%$ do total de exóticas), e foi subdivida em quatro subcategorias, a saber: utensílio, transporte, ferramentas e outras tecnologias (moldura para quadro de santos, esculturas religiosas, pólvora, pau de sebo, peneira, abano, incenso, borracha, limpeza de louça, inseticida, amadurecer frutos de outras plantas, pavio de candeeiro).

Para utensílio, das 26 espécies citadas, duas merecem destaque: a peroba (Aspidosperma sp.), com 26 indicações, e a jaqueira, com 25 indicações, ambas para confecção de móveis. Como meio de transporte foram citadas três espécies, com destaque para a sucupira, para a construção de carrode-boi, com sete citações. Em outras tecnologias, foram citadas 11 espécies, com destaque para a samambaia Curatella americana L., indicada para "arear louça", com 16 citações. Para a subcategoria ferramentas, foram citadas 16 espécies, a jaqueira foi a mais representativa, com 20 citações para a confecção de pilão e prensa.

Outros usos. As espécies citadas para a categoria outros usos se enquadraram em uso cultural e uso ornamental. Para o uso ornamental, foram indicadas quatro espécies, todas nativas da região, o ipê-roxo (Handroanthus sp. 1), a flor-de-Natal (Tibouchina francavillana Cogn.), o camarão (Casearia silvestris $\mathrm{Sw}$.) e flor-de-São-João (Senna sp.). Esta última espécie, além de servir de enfeite nos "tieiros" na época dos festejos juninos, sua florada é comemorada pelos moradores das comunidades como símbolo de prosperidade e fartura na produção rural durante o ano todo.

Das quatro espécies indicadas para ornamentação, a mais expressiva foi o ipê-roxo (Handroanthus sp.), citada por 10 especialistas como utilizada para enfeitar casas e santos. O fato de todas as espécies indicadas para 
ornamentação serem nativas permite inferir que a valorização da flora local ainda é alta, visto que a inserção de espécies exóticas e artificiais de uso ornamental não foi citada pelos especialistas. Apenas uma espécie foi enquadrada em uso cultural, com duas citações, o cambota-vermelho (Cupania revoluta Rolfe), que é empregada para fogueiras comunitárias na festa dedicada a São Pedro.

As lenhas que abastecem a festa tradicional dedicada a São Pedro provêm, no estado de Sergipe, tanto de madeiras oriundas de plantios quanto de extração direta em fragmentos florestais próximos às comunidades envolvidas nos festejos. O problema é que o estado de Sergipe ainda não possui uma política de gestão florestal consolidada, que possa permitir um manejo adequado das espécies madeireiras utilizadas para diversas finalidades (Gomes et al. 2006).

\section{Conclusões}

Os especialistas das áreas pesquisadas detêm um conhecimento amplo quanto ao uso de espécies madeireiras. Os dados etnológicos obtidos nesse trabalho nos permitem relacionar o conhecimento etnobotânico das plantas madeireiras encontradas nos diferentes hábitats com os aspectos culturais que ainda estão fortemente inseridos nas comunidades locais estudadas. Essas relações inseridas entre os especialistas populares e os recursos florestais se devem provavelmente a ideia de que as diferentes gerações que viveram e ainda vivem nas comunidades do agreste sergipano introduziram em seu cotidiano diferentes formas de usos e seletividade para o uso da flora madeireira disponível na região.

\section{REFERÊNCIAS}

Aguiar-Netto, A.O. 2006. Descrição geral da sub-bacia hidrográfica do rio Poxim. In: J.P.H. Alves, C.A.B. Garcia, A.O. Aguiar Netto \& R.A. Ferreira (eds), Diagnóstico e Avaliação da Sub-bacia hidrográfica do Rio Poxim. EDUFS/ FAPESE, Aracaju, p. 11-28.

Aguillar, S. \& Condit, R. 2001. Use of native tree species by na Hispanic community in Panama. Enonomic Botany 55: 223235.

Albuquerque, U.P.; Lucena, R.F.P. \& Alencar, N.L. 2010. Métodos e técnicas pra coleta de dados etnobiológicos. In: U.P. Albuquerque, R.F.P. Lucena \& L.V.F.C. Cunha (coords), Métodos e Técnicas na Pesquisa Etnobiológica $e$ Etnoecológica. Editora Livro Rápido/NUPPEA, Recife, p. 41-64.

Amorozo, M.C.M. \& Gély, A. 1988. Uso de plantas medicinais por caboclos do Baixo Amazonas, Barcarena, PA. Boletim do Museu Paraense Emílio Goeldi, Série Botânica 1(4): 47131.

APG III 2009. An update of the Angiosperm Phylogeny Group classification for the orders and families of flowering plants: APG III. Botanical Journal of the Linnean Society 161(2): 105-121.

Bailey, K. 1994. Methods of Social Research. 4 ed. The Free Press, New York.

Begossi, A. 1996. Use for ecological methods in ethnobotany: diversity indices. Economic Botany 50(3): 280-289.

Begossi, A.; Leitão-Filho, H.F. \& Richerson, P.J. 1993. Plant uses in a Brazilian coastal fishing community (Buzios Island). Journal of Ethnobiology 13(2): 233-256.

Begossi, A.; Hanazaki, N. \& Tamashiro, J.Y. 2002. Medicinal plants in the Atlantic Forest (Brazil) knowledge, use, and conservation. Human Ecology 30: 281-299.

Botrel, R.T.; Rodrigues, L.A.; Gomes L.J.; Carvalho, D.A. \& Fontes, M.A.L. 2006. Uso da vegetação nativa pela população local no município de Ingaí, MG, Brasil. Acta Botanica Brasilica 20(1): 143-156.

Caiafa, A.N. 2002. Composição Florística e Estrutura da Vegetação sobre Afloramento Rochoso do Parque Estadual da Serra do Brigadeiro, MG. Dissertação de Mestrado. Universidade Federal de Viçosa.

Carvalho, C.M. \& Vilar, J.C. 2005. Introdução - levantamento

Sitientibus série Ciências Biológicas 11(2): 239-253. 2011. da biota do Parque Nacional Serra de Itabaiana. In: C.M. Carvalho \& J.C. Vilar (eds), Parque Nacional Serra de Itabaiana: levantamento da biota. UFS/IBAMA, Aracaju, p. 9-14.

Combessie, J.C. 2004. O Método em Sociologia o Que é, Como Se Faz. Loyola, São Paulo.

Christo, A.G.; Guedes-Bruni, R.R. \& Fonseca-Kruel, V.S. 2006. Uso de recursos vegetais em comunidades rurais limítrofes à Reserva Biológica de Poço das Antas, Silva Jardim, Rio de Janeiro: estudo de caso na Gleba Aldeia Velha. Rodriguésia 57(3): 519-542.

Dantas, T.V.P.; Nascimento-Júnior, J.E.; Ribeiro, A.S. \& Prata, A.P.N. 2010. Florística e estrutura da vegetação arbustivo-arbórea das Areias Brancas do Parque Nacional Serra de Itabaiana/Sergipe, Brasil. Revista Brasileira de Botânica 33: 575-588.

Ferreira, R.A.; Santos, T.I.S. \& Santos, B.L. 2006. Análise florística e fitossociológica em nascentes e fragmentos de vegetação do rio Poxim. In: J.P.H. Alves, C.A.B. Garcia, A.O. Aguiar-Netto \& R.A. Ferreira (eds), Diagnóstico e Avaliação da Sub-bacia Hidrográfica do Rio Poxim. EDUFS/FAPESE, Aracaju, p. 137-162.

Figueiredo, G.M.; Leitão-Filho, H. \& Begossi, A. 1993. Ethnobotany of Atlantic Forest Coastal Communities: diversity of plant uses in Gamboa (Itacuruça Island, Brazil). Human Ecology 2(4): 419-430.

Fonseca-Kruel, V.S. \& Peixoto, A.L. 2004. Etnobotânica na Reserva Extrativista Marinha de Arraial do Cabo, RJ, Brasil. Acta Botanica Brasilica 18(1): 177-190.

Fraga, C.N. 2000. Ecologia, Fitogeografia e Conservação das Orchidaceae da Restinga do Estado do Espírito Santo. Dissertação de Mestrado. Museu Nacional da Universidade Federal do Rio de Janeiro.

Galeano, G. 2000. Forest use at the Pacific Coast of Choco, Colombia: a quantitative approach. Economy Botany 54(3): 358-376.

Godoy, I. 2008. Fogão a lenha: um passatempo agradável, uma rotina perigosa. Journal Brasileiro de Pneumologia 34(9): 637-638.

Gomes, L.J. \& Maroti, P.S. 2006. Estudo socioambiental nos povoados cajueiro e caroba, visando estratégias pra uso 
sustentável dos recursos naturais. In: J.P.H Alves, C.A.B. Garcia, A.O. Aguiar-Netto \& R.A. Ferreira (eds), Diagnóstico e Avaliação da Sub-bacia Hidrográfica do Rio Poxim. EDUFS/ FAPESE, Aracaju, p. 199-225.

Gomes, L. J.; Santana, V. \& Ribeiro, G. T. 2006. Unidades de conservação no estado de Sergipe. Revista da Fapese 2(1): 101-112.

Hanazaki, N.; Tamashiro, J.Y.; Leitão-Filho, H.F. \& Begossi, A. 2000. Diversity of plant uses in two Caiçara communities from the Atlantic Forest coast, Brazil. Biodiversity and Conservation 9: 597-615.

IBGE (Instituto Brasileiro de Geografia e Estatística) 2012. IBGE Cidades@ (Censo Agropecuário 2006).Disponível em: http:/ /www.ibge.gov.br/cidadesat/topwindow.htm?1; acesso em 3 jan. 2012.

Kakudidi, E.K. 2007. A study of plant materials used for house construction around Kibale National Park, western Uganda. African Journal of Ecology 45(1): 22-27.

Lévi-Strauss, C.O. 1987. Uso das plantas silvestres da América do Sul tropical. In: D. Ribeiro (ed.), Suma Etológica Brasileira. Vol. 1. 2 ed. FINEP/Vozes, Petrópolis, p. 29-46.

Lima, J.S.; Gomes, L.J. \& Maroti, P.S. 2009. Conhecimento e uso vegetais arbóreos: um estudo etnobotânico em comunidades rurais do entorno ao Parque Nacional Serra de Itabaiana, Sergipe, Brasil. Anais V Encontro Nordestino de Etnoecologia e Etnobiologia, Campina Grande.

Lima, R.X.; Silva, S.M.; Kuniyoshi, Y.S. \& Silva, L.B. 2000. Etnobiologia de comunidades continentais da Área de Proteção Ambiental de Guaraqueçaba, Paraná, Brasil. Etnoecológica 4(6): 33-55.

Macedo, R.S. 2006. Etnopesquisa Crítica, EtnopesquisaFormação. Líber Livro, Brasília, DF.

Marques, J.G.W. 2002. O olhar (des)multiplicado. O papel do interdisciplinar e do qualitativo na pesquisa etnobiológica e etnoecológica. In: M.C.M. Amorozo, L.C. MING \& S.M.P. Silva (eds), Métodos de Coleta e Análise de Dados em Etnobiologia, Etnoecologia e Disciplinas Correlatas. UNESP/ CNPq, Rio Claro, p. 31-46.

Moreira, M.A.C.; Moraes, M.R.; Silva, D.G.S.T.; Pinheiro, T.F.; Vasconcelos-Júnior, H.M.; Maia, L.F.L. \& Couto, D.V. 2008. Estudo comparativo de sintomas respiratórios e função pulmonar em pacientes com doença pulmonar obstrutiva crônica relacionada à exposição à fumaça de lenha e de tabaco. Jornal Brasileiro de Pneumologia 34(9): 667674.

Prance, G.T. 1987. Etnobotânica de algumas tribos amazônicas. In: D. Ribeiro (ed.), Suma Etnológica Brasileira. Edição atualizada do Handbook of South American Indians. Vol. 1 (Etnobiologia). 2 ed. FINEP/Vozes, Petrópolis, p. 119-133

Ramos, M.A.; Medeiros, P.M.; Almeida, A.L.S.; Feliciano, A.L.P. \& Albuquerque, U.P. 2008. Use and knowledge of fuelwood in an area of caatinga vegetation in NE Brazil. Biomass \& Bioenergy 32: 510-517.

Ramos, M.A.; Medeiros, P.M. \& Albuquerque, U.P. 2010. Métodos e técnicas aplicados a estudos etnobotânicos com recursos madeireiros. In: U.P. Albuquerque, R.F.P. Lucena \& L.V.F.C. Cunha (coords), Métodos e Técnicas na Pesquisa Etnobiológica e Etnoecológica. Editora Livro Rápido/ NUPPEA, Recife, p. 331-350.

Rossato, S.C.; Leitão-Filho, H.F. \& Begossi, A. 1999. Ethnobotany of caiçaras of the Atlantic Forest Coast (Brazil). Economic Botany 53(4): 387-395.

Sá e Silva, I.M.M.; Marangon, L.C.; Hanazaki, N. \& Albuquerque, U.P. 2009. Use and knowlegde of fuelwood in three rural caatinga (dryland) communities in NE Brazil. Environment, Development and Sustainability 11: 833-851.

Silva, A.J.R. \& Andrade, L.H.C. 2005. Etnobotânica nordestina: estudo comparativo da relação entre comunidades e vegetação na Zona do Litoral - Mata do Estado de Pernambuco, Brasil. Acta Botanica Brasilica 19(1): 45-60.

Souza, G.R. 2002. Florística do Estrato Arbustivo-Arbóreo em um Trecho de Floresta Atlântica, no Médio Paraíba do Sul, Município de Volta Redonda, Rio de Janeiro. Seropédica. Tese de Mestrado. Universidade Federal Rural do Rio de Janeiro.

Souza, V.C. \& Lorenzi, H. 2005. Botânica Sistemática. Guia ilustrado para identificação das famílias de angiospermas da flora brasileira, baseado em APG II. Instituto Plantarum, Nova Odessa.

Spata,A.V.2005. Métodos de Pesquisa: ciência do comportamento e diversidade humana. LTC, Rio de Janeiro.

TROPICOS 2010. Nomenclatural Data Base. Missouri Botanical Garden. Disponível em http://mobot.mobot.org/w3t/Search/ vast.html/; acesso em 13 jul. 2011

Vicente, A. 1999. Levantamento Florístico de um Fragmento Florestal na Serra de Itabaiana-Sergipe. Dissertação de Mestrado. Universidade Federal Rural de Pernambuco.

Vicente, A.; Araújo, G.M.M.; Lírio, G.P. \& Santos, S.C. 1997. Descrição parcial e preliminar dos hábitats da Serra de Itabaiana, Sergipe. Publicações Avulsas do Centro Acadêmico Livre de Biologia 1: 7-21.

Yaksic, M.S.; Tojo, M.; Cukier, A. \& Stelmach, R. 2003. Perfil de uma população brasileira com doença pulmonar obstrutiva crônica grave. Jornal de Pneumologia 29(2): 64-68. 
Apêndice. Espécies madeireiras uteis indicadas por especialista da região agreste do estado de Sergipe, classificadas em ordem alfabética de acordo com a família botânica. Legenda: Or. = Origem: N. = Nativa, E = exótica. N.C.= Número de citações. Usos: C $-\mathrm{Combustível,} \mathrm{CN}-$ Construção, T - Tecnologia, O - Outros usos. Indicação: C1 - Combustível residencial, C2 - Combustível para casa de farinha, C3 Combustível para olaria/padaria; CN1 - construção civil: a - esteio, b - caibro, c - ripa, d - porta, e - janela, f - cumeeira, g - finco, h varamento; CN2 - Construção rural: a - cerca, b - cancela, c - curral; T1 - Utensílio: a - móveis, b - peão e dados, c - poste de alta tensão, $\mathrm{d}$ - tamanco, e - caixão de defunto, f - viola, g - gaiola, arapuca, h - muleta, i - espeto, $\mathrm{j}$ - barril de cachaça, 1 - caixote de verdura, $\mathrm{m}$ caximbo; T2 - Transporte: a - canoa, b - carro-de-boi, c - carroça; T3- Outras tecnologias:a - moldura para quadro de santos, b - esculturas religiosas , c - pólvora, d - pau de sebo, e - peneira, f - abano, g - incenso, $\mathrm{h}$ - borracha, i - limpeza de louça, j - inseticida, 1 - amadurecer frutos de outras plantas, $\mathrm{m}$ - pavio de candeeiro; T4 - Ferramentas: a - cabo de enxada, b - cabo de foice, c - cabo de machado, $\mathrm{d}$ - cado de taca, e - cabo de vassoura, f - gamela, g - coronha de espingarda, h - pilão, i - prensa, j - colher de pau. O1- fogueira junina de São Pedro, O2 - ornamentação.

\begin{tabular}{|c|c|c|c|c|c|c|}
\hline Família/Nome científico & Nome popular & Or. & $\begin{array}{c}\text { N.C } \\
\cdot\end{array}$ & Uso & Indicação & $\begin{array}{l}\text { Qualidade } \\
\text { para uso }\end{array}$ \\
\hline Amarantaceae/Gomphrena sp. & Pau-pra-tudo & $\mathrm{N}$ & 2 & $\mathrm{C}$ & $\mathrm{C} 2$ & Ruim \\
\hline $\begin{array}{l}\text { Anacardiaceae/Anacardium } \\
\text { ocidentale L. }\end{array}$ & Cajueiro/Caju & E & 21 & $\mathrm{C}$ & $\mathrm{C} 2, \mathrm{C} 3$ & Boa \\
\hline $\begin{array}{l}\text { Anacardiaceae/Astronium } \\
\text { fraxinifolium S. Spreng. }\end{array}$ & Patizeiro/Pati & $\mathrm{N}$ & 1 & $\mathrm{C}$ & $\mathrm{C} 2$ & Média \\
\hline Anacardiaceae/Astronium sp. & Aderno & $\mathrm{N}$ & $\begin{array}{l}3 \\
5\end{array}$ & $\begin{array}{c}\mathrm{CN} \\
\mathrm{C}\end{array}$ & $\begin{array}{c}\text { CN1b, CN1c } \\
\text { C1 }\end{array}$ & $\begin{array}{l}\text { Boa } \\
\text { Boa }\end{array}$ \\
\hline $\begin{array}{l}\text { Anacardiaceae/Mangifera } \\
\text { indica L. }\end{array}$ & Manga & $\mathrm{E}$ & 18 & $\mathrm{C}$ & $\mathrm{C} 1, \mathrm{C} 2$ & Média \\
\hline $\begin{array}{l}\text { Anacardiaceae/Schinus } \\
\text { terebinthifolius } \text { Raddi }\end{array}$ & Aroeira & $\mathrm{E}$ & 3 & $\mathrm{C}$ & $\mathrm{C} 1$ & Média \\
\hline Anacardiaceae/Spondias sp. & Cajá & $\mathrm{E}$ & 1 & $\mathrm{~T}$ & T1b & Boa \\
\hline $\begin{array}{l}\text { Anacardiaceae/Tapirira } \\
\text { guianensis Aubl. }\end{array}$ & Pau-pombo & $\mathrm{N}$ & $\begin{array}{c}27 \\
9\end{array}$ & $\begin{array}{c}\mathrm{C} \\
\mathrm{CN}\end{array}$ & $\begin{array}{c}\mathrm{C} 2 \\
\mathrm{CN} 1 \mathrm{~d}\end{array}$ & $\begin{array}{l}\text { Média } \\
\text { Média }\end{array}$ \\
\hline $\begin{array}{l}\text { Annonaceae/ Annona } \\
\text { coriacea Mart. }\end{array}$ & Pinha & $\mathrm{E}$ & 2 & $\mathrm{C}$ & $\mathrm{C} 2$ & Média \\
\hline $\begin{array}{l}\text { Annonaceae/Annona muricata } \\
\text { L. }\end{array}$ & Graviola & $\mathrm{E}$ & 1 & $\mathrm{C}$ & $\mathrm{C} 2$ & Média \\
\hline Annonaceae/Annona sp. & Araticum-apê & $\mathrm{N}$ & 2 & $\mathrm{C}$ & $\mathrm{C} 1$ & Ruim \\
\hline $\begin{array}{l}\text { Annonaceae/Xylopia } \\
\text { frutescens Aubl. }\end{array}$ & Pindaíba & $\mathrm{N}$ & $\begin{array}{l}5 \\
4\end{array}$ & $\begin{array}{c}\mathrm{CN} \\
\mathrm{C}\end{array}$ & $\begin{array}{c}\text { CN1b, CN1c } \\
\mathrm{C} 2\end{array}$ & $\begin{array}{l}\text { Ruim } \\
\text { Média }\end{array}$ \\
\hline $\begin{array}{l}\text { Apocynaceae/ Aspidosperma } \\
\text { sp. }\end{array}$ & $\begin{array}{l}\text { Peroba/ } \\
\text { Folha-larga }\end{array}$ & $\mathrm{N}$ & $\begin{array}{c}5 \\
26 \\
3\end{array}$ & $\begin{array}{l}\mathrm{C} \\
\mathrm{T} \\
\mathrm{T}\end{array}$ & $\begin{array}{c}\mathrm{C} 2, \mathrm{C} 3 \\
\mathrm{~T} 1 \mathrm{a} \\
\mathrm{T} 4 \mathrm{a}\end{array}$ & $\begin{array}{c}\text { Muito boa } \\
\text { Boa } \\
\text { Boa }\end{array}$ \\
\hline $\begin{array}{l}\text { Apocynaceae/Hancornia } \\
\text { speciosa Gomes }\end{array}$ & $\begin{array}{l}\text { Mangabeira/ } \\
\text { Mangaba }\end{array}$ & $\mathrm{N}$ & 4 & $\mathrm{C}$ & $\mathrm{C} 1$ & Média \\
\hline Apocynaceae/Himatanthus sp. & Burra-leiteira & $\mathrm{N}$ & $\begin{array}{l}4 \\
4 \\
3\end{array}$ & $\begin{array}{l}\mathrm{CN} \\
\mathrm{T} \\
\mathrm{C}\end{array}$ & $\begin{array}{c}\text { CN1b, CN1c } \\
\text { T4f, T4j } \\
\text { C2 }\end{array}$ & $\begin{array}{l}\text { Ruim } \\
\text { Boa } \\
\text { Média }\end{array}$ \\
\hline $\begin{array}{l}\text { Apocynaceae/Himatanthus } \\
\text { bracteatus (DC.) Woodson }\end{array}$ & Bumba-boi & $\mathrm{N}$ & $\begin{array}{l}1 \\
4\end{array}$ & $\begin{array}{c}\mathrm{CN} \\
\mathrm{C}\end{array}$ & $\begin{array}{l}\text { CN1e, CN1f } \\
\text { C2 }\end{array}$ & $\begin{array}{l}\text { Ruim } \\
\text { Média }\end{array}$ \\
\hline $\begin{array}{l}\text { Arecaceae/Allagoptera } \\
\text { arenaria Kuntze }\end{array}$ & Caxindó & $\mathrm{N}$ & $\begin{array}{l}2 \\
2\end{array}$ & $\begin{array}{l}\mathrm{C} \\
\mathrm{T}\end{array}$ & $\begin{array}{c}\mathrm{C} 2 \\
\mathrm{~T} 1 \mathrm{~m}\end{array}$ & $\begin{array}{l}\text { Média } \\
\text { Boa }\end{array}$ \\
\hline Arecaceae/Allagoptera sp. & Burizeiro/Buri & $\mathrm{N}$ & $\begin{array}{c}13 \\
5\end{array}$ & $\begin{array}{l}\mathrm{T} \\
\mathrm{C}\end{array}$ & $\begin{array}{l}\text { T3e, T3f } \\
\quad \text { C2 }\end{array}$ & $\begin{array}{l}\text { Boa } \\
\text { Ruim }\end{array}$ \\
\hline Arecaceae/Cocos nucifera L. & Coqueiro & $\mathrm{E}$ & $\begin{array}{l}3 \\
3 \\
3\end{array}$ & $\begin{array}{c}\mathrm{T} \\
\mathrm{CN} \\
\mathrm{CN}\end{array}$ & $\begin{array}{l}\text { T1g } \\
\text { CN1f } \\
\text { CN2a }\end{array}$ & $\begin{array}{l}\text { Boa } \\
\text { Média } \\
\text { Média }\end{array}$ \\
\hline $\begin{array}{l}\text { Arecaceae/Elaeis guineensis } \\
\text { Jacq. }\end{array}$ & Dendê & $\mathrm{E}$ & $\begin{array}{l}3 \\
3\end{array}$ & $\begin{array}{c}\mathrm{T} \\
\mathrm{CN}\end{array}$ & $\begin{array}{l}\text { T3f } \\
\text { CN1f }\end{array}$ & $\begin{array}{l}\text { Boa } \\
\text { Média }\end{array}$ \\
\hline $\begin{array}{l}\text { Araliaceae/Schefflera } \\
\text { morototoni (Aubl.) Maguire }\end{array}$ & Galinheiro & $\mathrm{N}$ & $\begin{array}{c}13 \\
5\end{array}$ & $\begin{array}{l}\mathrm{T} \\
\mathrm{C}\end{array}$ & $\begin{array}{l}\mathrm{T} 1 \mathrm{~g} \\
\mathrm{C} 1\end{array}$ & $\begin{array}{l}\text { Boa } \\
\text { Média }\end{array}$ \\
\hline $\begin{array}{l}\text { Asteraceae/Acritopappus } \\
\text { confertus King \& Rob. }\end{array}$ & Fumo-brabo & $\mathrm{N}$ & $\begin{array}{l}4 \\
3\end{array}$ & $\begin{array}{l}\mathrm{C} \\
\mathrm{T}\end{array}$ & $\begin{array}{l}\mathrm{C} 2 \\
\mathrm{~T} 1 \mathrm{~g}\end{array}$ & $\begin{array}{c}\text { Ruim } \\
\text { Boa }\end{array}$ \\
\hline $\begin{array}{l}\text { Asteraceae/Eremanthus } \\
\text { incanus (Less.) Less. }\end{array}$ & Candeia & $\mathrm{N}$ & $\begin{array}{c}28 \\
7\end{array}$ & $\begin{array}{c}\mathrm{C} \\
\mathrm{CN}\end{array}$ & $\begin{array}{c}\mathrm{C} 1 \\
\mathrm{CN} 2 \mathrm{a}\end{array}$ & $\begin{array}{l}\text { Boa } \\
\text { Boa }\end{array}$ \\
\hline
\end{tabular}




\begin{tabular}{|c|c|c|c|c|c|c|}
\hline $\begin{array}{l}\text { Asteraceae/Gochnatia } \\
\text { oligocephala (Gardner) } \\
\text { Cabrera }\end{array}$ & Cega-machado & $\mathrm{N}$ & $\begin{array}{l}2 \\
3\end{array}$ & $\begin{array}{l}\mathrm{C} \\
\mathrm{T}\end{array}$ & $\begin{array}{l}\mathrm{C} 2 \\
\mathrm{~T} 1 \mathrm{a}\end{array}$ & $\begin{array}{l}\text { Média } \\
\text { Boa }\end{array}$ \\
\hline Bignoniaceae/Jacaranda sp. & $\begin{array}{l}\text { Caroba/Carobi } \\
\text { nha }\end{array}$ & $\mathrm{N}$ & $\begin{array}{l}2 \\
2\end{array}$ & $\begin{array}{c}\mathrm{CN} \\
\mathrm{C}\end{array}$ & $\begin{array}{l}\text { CN1b, CN1c } \\
\quad \mathrm{C} 1, \mathrm{C} 2\end{array}$ & $\begin{array}{l}\text { Média } \\
\text { Média }\end{array}$ \\
\hline $\begin{array}{l}\text { Bignoniaceae/Handroanthus } \\
\text { sp. } 1\end{array}$ & $\begin{array}{l}\text { Ipê-roxo/ } \\
\text { Pau d'arco }\end{array}$ & $\mathrm{N}$ & $\begin{array}{c}9 \\
18 \\
12 \\
10\end{array}$ & $\begin{array}{c}\mathrm{C} \\
\mathrm{CN} \\
\mathrm{T} \\
\mathrm{O}\end{array}$ & $\begin{array}{c}\text { C1 } \\
\text { CN1a, CN1b, CN1c, CN1f, } \\
\text { T4a, T4b } \\
\text { O2 }\end{array}$ & $\begin{array}{l}\text { Boa } \\
\text { Muito boa } \\
\text { Boa } \\
-\end{array}$ \\
\hline $\begin{array}{l}\text { Bignoniaceae/Handroanthus } \\
\text { sp. } 2\end{array}$ & $\begin{array}{l}\text { Ipê-branco/ } \\
\text { Pau-d'arco- } \\
\text { branco }\end{array}$ & $\mathrm{N}$ & $\begin{array}{l}2 \\
3\end{array}$ & $\begin{array}{c}\mathrm{C} \\
\mathrm{CN}\end{array}$ & $\begin{array}{c}\mathrm{C} 1 \\
\mathrm{CN} 1 \mathrm{~b}, \mathrm{CN} 1 \mathrm{c}\end{array}$ & $\begin{array}{l}\text { Boa } \\
\text { Boa }\end{array}$ \\
\hline $\begin{array}{l}\text { Bignoniaceae/Tecoma stans } \\
\text { (L.) Juss. ex Kunth }\end{array}$ & Ipê amarelo & $\mathrm{N}$ & $\begin{array}{l}3 \\
2 \\
2\end{array}$ & $\begin{array}{c}\mathrm{C} \\
\mathrm{CN} \\
\mathrm{T}\end{array}$ & $\begin{array}{c}\mathrm{C} 1 \\
\text { CN1b, CN1c } \\
\text { T4a }\end{array}$ & $\begin{array}{l}\text { Média } \\
\text { Boa } \\
\text { Média }\end{array}$ \\
\hline Bombacaceae/Eriotheca sp. & $\begin{array}{l}\text { Embiruçu/ } \\
\text { Imbiruçu }\end{array}$ & $\mathrm{N}$ & $\begin{array}{l}5 \\
3 \\
3 \\
9 \\
3 \\
2\end{array}$ & $\begin{array}{c}\mathrm{C} \\
\mathrm{CN} \\
\mathrm{CN} \\
\mathrm{T} \\
\mathrm{T} \\
\mathrm{T}\end{array}$ & $\begin{array}{c}\mathrm{C} 1 \\
\text { CN1b, CN1c, CN1f, } \\
\text { CN2b, CN2c } \\
\text { T1e } \\
\text { T3c } \\
\text { T4f }\end{array}$ & $\begin{array}{l}\text { Ruim } \\
\text { Média } \\
\text { Média } \\
\text { Boa } \\
\text { Média } \\
\text { Boa }\end{array}$ \\
\hline $\begin{array}{l}\text { Boraginaceae/Cordia nodosa } \\
\text { Lam. }\end{array}$ & Grão-de-galo & $\mathrm{N}$ & 2 & $\mathrm{C}$ & $\mathrm{C} 2$ & Ruim \\
\hline $\begin{array}{l}\text { Burseraceae/Protium } \\
\text { heptaphyllum (Aubl.) } \\
\text { Marchand }\end{array}$ & Amescla & $\mathrm{N}$ & $\begin{array}{c}4 \\
12\end{array}$ & $\begin{array}{l}\mathrm{C} \\
\mathrm{T}\end{array}$ & $\begin{array}{l}\text { C2 } \\
\text { T3g }\end{array}$ & $\begin{array}{l}\text { Média } \\
\text { Boa }\end{array}$ \\
\hline $\begin{array}{l}\text { Calophyllaceae/ Caraipa } \\
\text { densifolia Mart. }\end{array}$ & Camaçari & $\mathrm{N}$ & $\begin{array}{l}2 \\
8 \\
1\end{array}$ & $\begin{array}{l}\mathrm{C} \\
\mathrm{CN} \\
\mathrm{CN}\end{array}$ & $\begin{array}{c}\mathrm{C} 1 \\
\text { CN1b, CN1c, CN1f } \\
\text { CN1d, CN1e }\end{array}$ & $\begin{array}{l}\text { Boa } \\
\text { Muito boa } \\
\text { Boa }\end{array}$ \\
\hline $\begin{array}{l}\text { Calophyllaceae/Kielmeyera } \\
\text { cf. argentea Choisy }\end{array}$ & Pé-de-veado & $\mathrm{N}$ & 2 & $\mathrm{C}$ & $\mathrm{C} 2$ & Ruim \\
\hline Celastraceae/Mayetnus sp. & $\begin{array}{l}\text { Bom-nome/ } \\
\text { Carne-d'anta }\end{array}$ & $\mathrm{N}$ & $\begin{array}{l}5 \\
9 \\
4\end{array}$ & $\begin{array}{c}\mathrm{C} \\
\mathrm{CN} \\
\mathrm{T}\end{array}$ & $\begin{array}{c}\mathrm{C} 1 \\
\mathrm{CN} 1 \mathrm{~b}, \mathrm{CN} 1 \mathrm{c}, \mathrm{CN} 1 \mathrm{f} \\
\mathrm{T} 4 \mathrm{c}\end{array}$ & $\begin{array}{l}\text { Boa } \\
\text { Média } \\
\text { Boa }\end{array}$ \\
\hline $\begin{array}{l}\text { Chrysobalanaceae/Couерia } \\
\text { sp. }\end{array}$ & Oiti/Oiticoró & $\mathrm{N}$ & $\begin{array}{l}4 \\
4\end{array}$ & $\begin{array}{c}\mathrm{C} \\
\mathrm{CN}\end{array}$ & $\begin{array}{c}\mathrm{C} 2 \\
\mathrm{CN} 1 \mathrm{a}\end{array}$ & $\begin{array}{l}\text { Ruim } \\
\text { Boa }\end{array}$ \\
\hline $\begin{array}{l}\text { Chrysobalanaceae/Hirtella } \\
\text { ciliata Mart \& Zucc. }\end{array}$ & Bula-cinza & $\mathrm{N}$ & 9 & $\mathrm{C}$ & $\mathrm{C} 2$ & Ruim \\
\hline $\begin{array}{l}\text { Clusiaceae/Clusia nemorosa } \\
\text { G.Mey. }\end{array}$ & Sapateiro & $\mathrm{N}$ & $\begin{array}{l}4 \\
5\end{array}$ & $\begin{array}{c}\mathrm{C} \\
\mathrm{CN}\end{array}$ & $\begin{array}{c}\mathrm{C} 1 \\
\mathrm{CN} 1 \mathrm{~d}\end{array}$ & $\begin{array}{l}\text { Boa } \\
\text { Média }\end{array}$ \\
\hline $\begin{array}{l}\text { Clusiaceae/Symphonia } \\
\text { globulifera L. f. }\end{array}$ & Landri & $\mathrm{N}$ & $\begin{array}{l}2 \\
2 \\
1 \\
2\end{array}$ & $\begin{array}{c}\mathrm{C} \\
\mathrm{CN} \\
\mathrm{T} \\
\mathrm{T}\end{array}$ & $\begin{array}{c}\text { C2 } \\
\text { CN1d, CN1f } \\
\text { T1a } \\
\text { T3h }\end{array}$ & $\begin{array}{l}\text { Média } \\
\text { Média } \\
\text { Boa } \\
\text { Boa }\end{array}$ \\
\hline $\begin{array}{l}\text { Dilleniaceae/Curatella } \\
\text { americana } \mathrm{L} \text {. }\end{array}$ & $\begin{array}{l}\text { Sambaíba/ } \\
\text { Lava-prato }\end{array}$ & $\mathrm{N}$ & $\begin{array}{c}12 \\
1 \\
16 \\
12 \\
8\end{array}$ & $\begin{array}{c}\mathrm{C} \\
\mathrm{CN} \\
\mathrm{T} \\
\mathrm{T} \\
\mathrm{T}\end{array}$ & $\begin{array}{l}\mathrm{C} 2 \\
\mathrm{CN} 2 \mathrm{a} \\
\mathrm{T} 3 \mathrm{i} \\
\mathrm{T} 3 \mathrm{a} \\
\mathrm{T} 3 \mathrm{~b}\end{array}$ & $\begin{array}{l}\text { Ruim } \\
\text { Ruim } \\
\text { Boa } \\
\text { Boa } \\
\text { Média }\end{array}$ \\
\hline $\begin{array}{l}\text { Dilleniaceae/Davilla flexuosa } \\
\text { A. St.-Hil. }\end{array}$ & $\begin{array}{l}\text { Chapéu-de- } \\
\text { boneca }\end{array}$ & $\mathrm{N}$ & 1 & $\mathrm{C}$ & $\mathrm{C} 2$ & Média \\
\hline $\begin{array}{l}\text { Erythroxylaceae / } \\
\text { Erythroxylum sp. }\end{array}$ & Cocão & $\mathrm{N}$ & $\begin{array}{c}8 \\
19\end{array}$ & $\begin{array}{c}\mathrm{C} \\
\mathrm{CN}\end{array}$ & $\begin{array}{c}\mathrm{C} 2 \\
\text { CN1a, CN1b, CN1f, CN1g }\end{array}$ & $\begin{array}{c}\text { Boa } \\
\text { Muito boa }\end{array}$ \\
\hline $\begin{array}{l}\text { Euphorbiaceae/Croton } \\
\text { heliotropiifolius } \text { Kunth }\end{array}$ & Velande & $\mathrm{E}$ & $\begin{array}{l}1 \\
2\end{array}$ & $\begin{array}{l}\mathrm{C} \\
\mathrm{T}\end{array}$ & $\begin{array}{c}\mathrm{C} 1 \\
\mathrm{~T} 1 \mathrm{~m}\end{array}$ & $\begin{array}{l}\text { Média } \\
\text { Boa }\end{array}$ \\
\hline $\begin{array}{l}\text { Euphorbiaceae/Pera glabrata } \\
\text { Poepp. ex Baill. }\end{array}$ & $\begin{array}{l}\text { Ganhador/ } \\
\text { Pataqueiro }\end{array}$ & $\mathrm{N}$ & $\begin{array}{l}6 \\
3\end{array}$ & $\begin{array}{c}\mathrm{C} \\
\mathrm{CN}\end{array}$ & $\begin{array}{c}\mathrm{C} 1 \\
\mathrm{CN} 1 \mathrm{~b}, \mathrm{CN} 1 \mathrm{c}, \mathrm{CN} 1 \mathrm{f}\end{array}$ & $\begin{array}{l}\text { Boa } \\
\text { Boa }\end{array}$ \\
\hline
\end{tabular}




\begin{tabular}{|c|c|c|c|c|c|c|}
\hline Euphorbiaceae/Croton sp. & $\begin{array}{l}\text { Marmeleiro/ } \\
\text { Marmelo }\end{array}$ & $\mathrm{N}$ & $\begin{array}{l}6 \\
4 \\
5\end{array}$ & $\begin{array}{c}\mathrm{T} \\
\mathrm{C} \\
\mathrm{CN}\end{array}$ & $\begin{array}{l}\mathrm{T} 1 \mathrm{~h} \\
\mathrm{C} 2 \\
\mathrm{CN} 2 \mathrm{a}\end{array}$ & $\begin{array}{l}\text { Boa } \\
\text { Média } \\
\text { Boa }\end{array}$ \\
\hline $\begin{array}{l}\text { Hernandiaceae/Sparattantheli } \\
\text { um botocudorum Mart. }\end{array}$ & Arco-de-barril & $\mathrm{N}$ & $\begin{array}{l}1 \\
1\end{array}$ & $\begin{array}{l}\mathrm{C} \\
\mathrm{T}\end{array}$ & $\begin{array}{l}\mathrm{C} 2 \\
\mathrm{~T} 1 \mathrm{j}\end{array}$ & $\begin{array}{l}\text { Média } \\
\text { Boa }\end{array}$ \\
\hline $\begin{array}{l}\text { Humiriaceae/Humiria } \\
\text { balsamifera Aubl. }\end{array}$ & $\begin{array}{l}\text { Curesmeira/ } \\
\text { Cu-de-nego }\end{array}$ & $\mathrm{N}$ & 2 & $\mathrm{C}$ & $\mathrm{C} 1$ & Média \\
\hline $\begin{array}{l}\text { Hypericaceae/Vismia } \\
\text { guianensis (Aubl.) Pers. }\end{array}$ & Alcafroa & $\mathrm{N}$ & 1 & $\mathrm{C}$ & $\mathrm{C} 2$ & Ruim \\
\hline $\begin{array}{l}\text { Lauraceae/Ocotea gardneri } \\
\text { (Meisn.) Mez }\end{array}$ & Louro-pimenta & $\mathrm{N}$ & $\begin{array}{l}6 \\
3\end{array}$ & $\begin{array}{c}\mathrm{C} \\
\mathrm{CN}\end{array}$ & $\begin{array}{c}\mathrm{C} 2 \\
\mathrm{CN} 1 \mathrm{~b}, \mathrm{CN} 1 \mathrm{c}\end{array}$ & $\begin{array}{l}\text { Média } \\
\text { Boa }\end{array}$ \\
\hline Lauraceae/Ocotea sp. & Louro-jiboia & $\mathrm{N}$ & $\begin{array}{l}2 \\
5\end{array}$ & $\begin{array}{c}\mathrm{C} \\
\mathrm{CN}\end{array}$ & $\begin{array}{c}\mathrm{C} 2 \\
\mathrm{CN} 1 \mathrm{f}\end{array}$ & $\begin{array}{l}\text { Média } \\
\text { Boa }\end{array}$ \\
\hline $\begin{array}{l}\text { Lauraceae/Persea americana } \\
\text { Mill. }\end{array}$ & Abacate & $\mathrm{E}$ & 1 & $\mathrm{C}$ & $\mathrm{C} 2$ & Média \\
\hline $\begin{array}{l}\text { Lecytidadeceae/Eschweilera } \\
\text { sp. }\end{array}$ & Imbira & $\mathrm{N}$ & $\begin{array}{l}3 \\
5\end{array}$ & $\begin{array}{l}\mathrm{C} \\
\mathrm{T}\end{array}$ & $\begin{array}{l}\mathrm{C} 2 \\
\mathrm{~T} 4 \mathrm{~d}\end{array}$ & $\begin{array}{l}\text { Média } \\
\text { Boa }\end{array}$ \\
\hline $\begin{array}{l}\text { Lecytidadeceae/Escweleira } \\
\text { ovata(Cambess.) Miers }\end{array}$ & Biriba/Biribê & $\mathrm{N}$ & $\begin{array}{c}10 \\
24 \\
20 \\
4\end{array}$ & $\begin{array}{c}\mathrm{C} \\
\mathrm{CN} \\
\mathrm{CN} \\
\mathrm{T}\end{array}$ & $\begin{array}{c}\mathrm{C} 1 \\
\text { CN1a, CN1f } \\
\text { CN2a } \\
\text { T1c }\end{array}$ & $\begin{array}{c}\text { Boa } \\
\text { Boa } \\
\text { Boa } \\
\text { Média }\end{array}$ \\
\hline Lecytidadeceae/Lecythis sp. & $\begin{array}{l}\text { Canela-de- } \\
\text { tabuleiro }\end{array}$ & $\mathrm{N}$ & 3 & $\mathrm{C}$ & $\mathrm{C} 1, \mathrm{C} 2$ & Boa \\
\hline $\begin{array}{l}\text { Lecytidadeceae/Lecythis } \\
\text { pisonis Cambess. }\end{array}$ & Sapucaia-coco & $\mathrm{N}$ & $\begin{array}{l}4 \\
6 \\
4\end{array}$ & $\begin{array}{l}\mathrm{C} \\
\mathrm{CN} \\
\mathrm{CN}\end{array}$ & $\begin{array}{c}\mathrm{C} 2 \\
\text { CN1a, CN1b, CN1f, CN1g } \\
\text { CN2a }\end{array}$ & $\begin{array}{l}\text { Boa } \\
\text { Boa } \\
\text { Boa }\end{array}$ \\
\hline $\begin{array}{l}\text { Leguminosae /Andira nitida } \\
\text { Mart. ex Benth. }\end{array}$ & Angelim & $\mathrm{N}$ & $\begin{array}{l}7 \\
8 \\
2\end{array}$ & $\begin{array}{l}\mathrm{C} \\
\mathrm{CN} \\
\mathrm{CN}\end{array}$ & $\begin{array}{c}\mathrm{C} 2 \\
\mathrm{CN} 1 \mathrm{~b}, \mathrm{CN} 1 \mathrm{c} \\
\mathrm{CN} 2 \mathrm{~b}, \mathrm{CN} 2 \mathrm{c}\end{array}$ & $\begin{array}{c}\text { Ruim } \\
\text { Boa } \\
\text { Boa }\end{array}$ \\
\hline $\begin{array}{l}\text { Leguminosae /Bauhinia } \\
\text { cheilantha (Bong.) Steud. }\end{array}$ & Miroró & $\mathrm{N}$ & $\begin{array}{l}1 \\
3 \\
1 \\
1\end{array}$ & $\begin{array}{c}\mathrm{C} \\
\mathrm{CN} \\
\mathrm{CN} \\
\mathrm{T}\end{array}$ & $\begin{array}{c}\mathrm{C} 1 \\
\mathrm{CNb}, \mathrm{CN} 1 \mathrm{c} \\
\mathrm{CN} 2 \mathrm{a} \\
\mathrm{T} 2 \mathrm{~b}\end{array}$ & $\begin{array}{c}\text { Boa } \\
\text { Boa } \\
\text { Boa } \\
\text { Média }\end{array}$ \\
\hline Leguminosae /Bowdichia sp. & Sucupira-açu & $\mathrm{N}$ & $\begin{array}{l}3 \\
5\end{array}$ & $\begin{array}{c}\mathrm{C} \\
\mathrm{CN}\end{array}$ & $\begin{array}{c}\mathrm{C} 1 \\
\text { CN1a, CN1b, CN1c, } \\
\text { CN1f, CN1g }\end{array}$ & $\begin{array}{l}\text { Boa } \\
\text { Boa } \\
\text { Boa }\end{array}$ \\
\hline $\begin{array}{l}\text { Leguminosae /Bowdichia } \\
\text { virgilioides Kunth }\end{array}$ & $\begin{array}{l}\text { Sucupira/ } \\
\text { Sucupira- } \\
\text { verdadeira }\end{array}$ & $\mathrm{N}$ & $\begin{array}{c}7 \\
13 \\
30\end{array}$ & $\begin{array}{c}\mathrm{T} \\
\mathrm{C} \\
\mathrm{CN}\end{array}$ & $\begin{array}{c}\mathrm{T} 2 \mathrm{~b} \\
\mathrm{C} 3 \\
\mathrm{CN} 1 \mathrm{a}, \mathrm{CN} 1 \mathrm{~b}, \mathrm{CN} 1 \mathrm{f}, \mathrm{CN} 1 \mathrm{~g}\end{array}$ & $\begin{array}{c}\text { Boa } \\
\text { Boa } \\
\text { Muito boa }\end{array}$ \\
\hline $\begin{array}{l}\text { Leguminosae /Caesalpinia } \\
\text { ferrea Mart. ex. Tul. }\end{array}$ & Pau-ferro & $\mathrm{N}$ & 8 & $\mathrm{C}$ & $\mathrm{C} 2$ & Média \\
\hline $\begin{array}{l}\text { Leguminosae /Cassia grandis } \\
\text { L. f. }\end{array}$ & Canafístula & $\mathrm{N}$ & $\begin{array}{l}4 \\
3 \\
9\end{array}$ & $\begin{array}{c}\mathrm{T} \\
\mathrm{C} \\
\mathrm{CN}\end{array}$ & $\begin{array}{c}\text { T3j } \\
\text { C2 } \\
\text { CN1b, CN1c, CN1f }\end{array}$ & $\begin{array}{l}\text { Boa } \\
\text { Média } \\
\text { Boa }\end{array}$ \\
\hline $\begin{array}{l}\text { Leguminosae /Chamaecrista } \\
\text { cytisoides DC. }\end{array}$ & Cascudinho & $\mathrm{N}$ & $\begin{array}{l}3 \\
2\end{array}$ & $\begin{array}{c}\mathrm{C} \\
\mathrm{CN}\end{array}$ & $\begin{array}{l}\mathrm{C} 2 \\
\mathrm{CN} 2 \mathrm{a}\end{array}$ & $\begin{array}{l}\text { Média } \\
\text { Média }\end{array}$ \\
\hline $\begin{array}{l}\text { Leguminosae /Diptychandra } \\
\text { epunctata Tul. }\end{array}$ & Sucupirinha & $\mathrm{N}$ & $\begin{array}{l}4 \\
4 \\
4\end{array}$ & $\begin{array}{r}\mathrm{CN} \\
\mathrm{CN} \\
\mathrm{C}\end{array}$ & $\begin{array}{c}\text { CN1a, CN1b, CN1c, CN1f } \\
\text { CN2a } \\
\text { C1 }\end{array}$ & $\begin{array}{l}\text { Boa } \\
\text { Boa } \\
\text { Boa }\end{array}$ \\
\hline $\begin{array}{l}\text { Leguminosae /Enterolobium } \\
\text { cf. timbouva Mart. }\end{array}$ & $\begin{array}{l}\text { Orelha-de- } \\
\text { macaco }\end{array}$ & $\mathrm{N}$ & 1 & $\mathrm{C}$ & $\mathrm{C} 2$ & Média \\
\hline $\begin{array}{l}\text { Leguminosae /Enterolobium } \\
\text { sp. }\end{array}$ & $\begin{array}{l}\text { Timbopé/ } \\
\text { Maria-farinha }\end{array}$ & $\mathrm{N}$ & $\begin{array}{c}4 \\
11\end{array}$ & $\begin{array}{l}\mathrm{C} \\
\mathrm{T}\end{array}$ & $\begin{array}{c}\mathrm{C} 1 \\
\mathrm{~T} 3 \mathrm{c}, \mathrm{T} 31\end{array}$ & $\begin{array}{c}\text { Média } \\
\text { Boa }\end{array}$ \\
\hline Leguminosae /Erythrina sp. & Mulungu & $\mathrm{N}$ & $\begin{array}{l}3 \\
3 \\
3\end{array}$ & $\begin{array}{l}\mathrm{T} \\
\mathrm{T} \\
\mathrm{C}\end{array}$ & $\begin{array}{l}\text { T1d } \\
\text { T4f } \\
\text { C1 }\end{array}$ & $\begin{array}{l}\text { Média } \\
\text { Média } \\
\text { Boa }\end{array}$ \\
\hline $\begin{array}{l}\text { Leguminosae /Hymenaea } \\
\text { courbaril L. }\end{array}$ & Jatobá & $\mathrm{N}$ & $\begin{array}{l}3 \\
6\end{array}$ & $\begin{array}{c}\mathrm{C} \\
\mathrm{CN}\end{array}$ & $\begin{array}{c}\mathrm{C} 1 \\
\mathrm{CN} 1 \mathrm{~b}, \mathrm{CN} 1 \mathrm{c}\end{array}$ & $\begin{array}{l}\text { Média } \\
\text { Boa }\end{array}$ \\
\hline
\end{tabular}

Sitientibus série Ciências Biológicas 11(2): 239-253. 2011. 


\begin{tabular}{|c|c|c|c|c|c|c|}
\hline Leguminosae /Inga sp.1 & - & $\mathrm{N}$ & 8 & $\mathrm{C}$ & $\mathrm{C} 2$ & Média \\
\hline \multirow{2}{*}{ Leguminosae /Inga sp.2 } & \multirow{2}{*}{ Ingá-branco } & \multirow{2}{*}{$\mathrm{N}$} & 4 & $\mathrm{C}$ & $\mathrm{C} 2$ & Média \\
\hline & & & 3 & $\mathrm{CN}$ & $\mathrm{CN} 2 \mathrm{a}$ & Média \\
\hline $\begin{array}{l}\text { Leguminosae /Machaerium } \\
\text { sp. }\end{array}$ & $\begin{array}{l}\text { Espinheiro- } \\
\text { triste }\end{array}$ & $\mathrm{N}$ & 1 & $\mathrm{C}$ & $\mathrm{C} 2$ & Média \\
\hline \multirow{3}{*}{$\begin{array}{l}\text { Leguminosae /Mimosa } \\
\text { caesalpiniifolia Benth. }\end{array}$} & \multirow[t]{3}{*}{ Sabiá } & \multirow[t]{3}{*}{$\mathrm{E}$} & 10 & $\mathrm{C}$ & $\mathrm{C} 1, \mathrm{C} 2$ & Boa \\
\hline & & & 13 & $\mathrm{CN}$ & $\mathrm{CN} 2 \mathrm{a}$ & Boa \\
\hline & & & 2 & $\mathrm{~T}$ & T1i & Boa \\
\hline Leguminosae /Mimosa sp. & Espinheiro & $\mathrm{N}$ & 3 & $\mathrm{C}$ & $\mathrm{C} 2$ & Média \\
\hline \multirow{3}{*}{$\begin{array}{l}\text { Leguminosae /Mimosa } \\
\text { tenuiflora (Willd.) Poir. }\end{array}$} & \multirow[t]{3}{*}{ Jurema } & \multirow[t]{3}{*}{$\mathrm{E}$} & 9 & $\mathrm{C}$ & $\mathrm{C} 3$ & Boa \\
\hline & & & 3 & $\mathrm{CN}$ & $\mathrm{CN} 2 \mathrm{a}$ & Boa \\
\hline & & & 2 & $\mathrm{~T}$ & $\mathrm{~T} 4 \mathrm{~b}$ & Boa \\
\hline \multirow{4}{*}{$\begin{array}{l}\text { Leguminosae /Sclerolobium } \\
\text { sp.1 }\end{array}$} & \multirow[t]{4}{*}{ Ingaporca } & \multirow[t]{4}{*}{$\mathrm{N}$} & 1 & $\mathrm{C}$ & $\mathrm{C} 2$ & Boa \\
\hline & & & 7 & $\mathrm{CN}$ & CN1f & Média \\
\hline & & & 11 & $\mathrm{CN}$ & CN1d & Média \\
\hline & & & 4 & $\mathrm{~T}$ & $\mathrm{~T} 2 \mathrm{~b}$ & Boa \\
\hline \multirow{3}{*}{$\begin{array}{l}\text { Leguminosae /Sclerolobium } \\
\text { sp.2 }\end{array}$} & \multirow{3}{*}{$\begin{array}{l}\text { Ingaçu/Pau- } \\
\text { fava }\end{array}$} & \multirow[t]{3}{*}{$\mathrm{N}$} & 16 & $\mathrm{C}$ & $\mathrm{C} 2$ & Média \\
\hline & & & 7 & $\mathrm{CN}$ & CN1d & Média \\
\hline & & & 4 & $\mathrm{~T}$ & $\mathrm{~T} 2 \mathrm{~b}, \mathrm{~T} 2 \mathrm{c}$ & Boa \\
\hline \multirow[t]{2}{*}{ Leguminosae /Senna sp. } & Flor-de-São- & \multirow[t]{2}{*}{$\mathrm{N}$} & 2 & $\mathrm{C}$ & $\mathrm{C} 1$ & Média \\
\hline & João & & 5 & $\mathrm{O}$ & $\mathrm{O} 1 \mathrm{~b}$ & - \\
\hline \multirow{4}{*}{$\begin{array}{l}\text { Leguminosae } \\
\text { /Stryphnodendron adstringens } \\
\text { Mart. (Coville) } \\
\text { Leguminosae /Swartzia sp. }\end{array}$} & Babatenã/ & \multirow[t]{2}{*}{$\mathrm{N}$} & 5 & $\mathrm{C}$ & $\mathrm{C} 1$ & Boa \\
\hline & Barbatimão & & 2 & $\mathrm{CN}$ & CN1a, CN1g & Boa \\
\hline & Meiú/ & $\mathrm{N}$ & 5 & $\mathrm{C}$ & $\mathrm{C} 2$ & Boa \\
\hline & $\begin{array}{l}\text { Língua-de- } \\
\text { vaca }\end{array}$ & & 4 & $\mathrm{CN}$ & $\begin{array}{l}\text { CN1a, CN1b, CN1c, } \\
\text { CN1f, CN1g }\end{array}$ & $\begin{array}{l}\text { Média } \\
\text { Média }\end{array}$ \\
\hline $\begin{array}{l}\text { Leguminosae /Hymenolobium } \\
\text { alagoanum Ducke }\end{array}$ & $\begin{array}{l}\text { Carrasco-de- } \\
\text { Caatinga }\end{array}$ & $\mathrm{N}$ & 3 & $\mathrm{C}$ & $\mathrm{C} 1$ & Boa \\
\hline Leguminosae /Parkia sp. & Juerana/Mijon & $\mathrm{N}$ & 8 & $\mathrm{C}$ & $\mathrm{C} 2$ & Ruim \\
\hline & $\mathrm{a}$ & & 2 & $\mathrm{CN}$ & CN1d, CN1e & Média \\
\hline & & & 2 & $\mathrm{~T}$ & T11 & Boa \\
\hline Leguminosae / Simarouba sp. & Paraíba & $\mathrm{N}$ & 12 & $\mathrm{C}$ & $\mathrm{C} 2$ & Ruim \\
\hline & & & 14 & $\mathrm{CN}$ & CN1d & Boa \\
\hline & & & 17 & $\mathrm{~T}$ & T1d, T1e, T4j, T4e & Média \\
\hline $\begin{array}{l}\text { Malpighiaceae/Byrsonima } \\
\text { coccolobifolia Kunth }\end{array}$ & $\begin{array}{l}\text { Murici-de- } \\
\text { tabuleiro }\end{array}$ & $\mathrm{N}$ & 8 & $\mathrm{C}$ & $\mathrm{C} 1$ & Boa \\
\hline Malpighiaceae/Byrsonima & Murici-da- & $\mathrm{N}$ & 31 & $\mathrm{C}$ & $\mathrm{C} 1, \mathrm{C} 2$ & Muito Boa \\
\hline sericea DC. & mata & & 24 & $\mathrm{CN}$ & CN1f & Média \\
\hline & & & 20 & $\mathrm{CN}$ & $\mathrm{CN} 2 \mathrm{a}$ & Boa \\
\hline & & & 7 & $\mathrm{~T}$ & T1a & Boa \\
\hline Malpighiaceae/Byrsonima sp. & Murici-branco & $\mathrm{N}$ & 4 & $\mathrm{C}$ & $\mathrm{C} 1$ & Boa \\
\hline Malvaceae/Hibiscus sp. & Algodão-criolo & $\mathrm{E}$ & 4 & $\mathrm{C}$ & $\mathrm{C} 2$ & Ruim \\
\hline & & & 8 & $\mathrm{~T}$ & $\mathrm{~T} 3 \mathrm{~m}$ & Boa \\
\hline Melastomataceae/Tibouchina & Flor-de-Natal & $\mathrm{N}$ & 2 & $\mathrm{C}$ & $\mathrm{C} 1$ & Média \\
\hline francavillana Cogn. & & & 4 & $\mathrm{O}$ & $\mathrm{O} 2$ & - \\
\hline Meliaceae/Cedrela sp. & Cedro & $\mathrm{E}$ & 2 & $\mathrm{C}$ & $\mathrm{C} 1$ & Boa \\
\hline & & & 14 & $\mathrm{CN}$ & CN1d & Boa \\
\hline & & & 14 & $\mathrm{~T}$ & T1a, T3a & Muito boa \\
\hline Moraceae/Artocarpus & Jaqueira/Jaca & $\mathrm{E}$ & 14 & $\mathrm{C}$ & $\mathrm{C} 1$ & Muito boa \\
\hline heterophyllus Lam. & & & 18 & $\mathrm{CN}$ & $\mathrm{CN} 2 \mathrm{~b}, \mathrm{CN} 2 \mathrm{c}$ & Boa \\
\hline & & & 25 & $\mathrm{CN}$ & CN1d, CN1e & Boa \\
\hline & & & 25 & $\mathrm{~T}$ & T1a & Muito boa \\
\hline & & & 20 & $\mathrm{~T}$ & T4h,T4i & Boa \\
\hline Moraceae/Brosimum sp. & Canduru/Cond & $\mathrm{N}$ & 1 & $\mathrm{C}$ & $\mathrm{C} 2$ & Média \\
\hline & uru & & 5 & $\mathrm{~T}$ & $\mathrm{~T} 4 \mathrm{c}$ & Boa \\
\hline
\end{tabular}




\begin{tabular}{|c|c|c|c|c|c|c|}
\hline Moraceae/Clarisia sp. & Oiticica & $\mathrm{N}$ & 3 & $\mathrm{C}$ & $\mathrm{C} 2$ & Ruim \\
\hline \multirow[t]{2}{*}{ Moraceae/Ficus sp. } & Tapiroroca/ & $\mathrm{N}$ & 1 & $\mathrm{C}$ & $\mathrm{C} 1$ & Boa \\
\hline & Pororoca & & 3 & $\mathrm{CN}$ & $\mathrm{CN} 1 \mathrm{~b}, \mathrm{CN} 1 \mathrm{c}, \mathrm{CN} 1 \mathrm{~d}, \mathrm{CN} 1 \mathrm{f}$ & Boa \\
\hline $\begin{array}{l}\text { Myrtaceae/Calyptranthes } \\
\text { clusiifolia O. Berg }\end{array}$ & Murta-branca & $\mathrm{N}$ & 3 & $\mathrm{C}$ & $\mathrm{C} 2$ & Boa \\
\hline \multirow{2}{*}{$\begin{array}{l}\text { Myrtaceae/Campomanesia } \\
\text { guaviroba Kiaersk. }\end{array}$} & Guabiraba/ & $\mathrm{N}$ & 7 & $\mathrm{C}$ & $\mathrm{C} 2$ & Boa \\
\hline & Gobiraba & & 4 & $\mathrm{CN}$ & $\mathrm{CN} 2 \mathrm{a}$ & Boa \\
\hline \multirow[t]{2}{*}{ Myrtaceae/Campomanesia sp. } & Banheira & $\mathrm{N}$ & 4 & $\mathrm{C}$ & $\mathrm{C} 1$ & Boa \\
\hline & & & 5 & $\mathrm{CN}$ & CN1a, CN1f, CN1g & Boa \\
\hline \multirow[t]{3}{*}{ Myrtaceae/Eucalyptus sp. } & Eucalipto & $\mathrm{E}$ & 2 & $\mathrm{C}$ & $\mathrm{C} 2$ & Média \\
\hline & & & 1 & $\mathrm{CN}$ & CN1d & Média \\
\hline & & & 1 & $\mathrm{~T}$ & T1a & Boa \\
\hline Myrtaceae/Eugenia sp. & $\begin{array}{l}\text { Murtinha-de- } \\
\text { Tabuleiro }\end{array}$ & $\mathrm{N}$ & 5 & $\mathrm{C}$ & $\mathrm{C} 2$ & Boa \\
\hline $\begin{array}{l}\text { Myrtaceae/Myrcia fallax } \\
\text { (Rich.) DC. }\end{array}$ & $\begin{array}{l}\text { Murta-de- } \\
\text { Tabuleiro }\end{array}$ & $\mathrm{N}$ & 4 & $\mathrm{C}$ & $\mathrm{C} 2$ & Boa \\
\hline Myrtaceae/Myrcia sp. & $\begin{array}{l}\text { Cambuí-da- } \\
\text { mata }\end{array}$ & $\mathrm{N}$ & 3 & $\mathrm{C}$ & $\mathrm{C} 1$ & Média \\
\hline $\begin{array}{l}\text { Myrtaceae/Myrciaria } \\
\text { cauliflora } \mathrm{L} \text {. }\end{array}$ & Jabuticaba & $\mathrm{E}$ & 1 & $\mathrm{C}$ & $\mathrm{C} 2$ & Média \\
\hline $\begin{array}{l}\text { Myrtaceae/Plinia edulis } \\
\text { (Vell.) Sobral }\end{array}$ & $\begin{array}{l}\text { Cambucá/ } \\
\text { Cumbuqui }\end{array}$ & $\mathrm{N}$ & 3 & $\mathrm{C}$ & $\mathrm{C} 2$ & Média \\
\hline Myrtaceae/Psidium guajava & Goiabeira/goia & $\mathrm{E}$ & 9 & $\mathrm{C}$ & $\mathrm{C} 1$ & Boa \\
\hline L. & ba & & 2 & $\mathrm{~T}$ & $\mathrm{~T} 1 \mathrm{~b}$ & Média \\
\hline Myrtaceae/Psidium guianense & Araçá-goiaba/ & $\mathrm{N}$ & 27 & $\mathrm{C}$ & $\mathrm{C} 1, \mathrm{C} 2$ & Boa \\
\hline \multirow[t]{2}{*}{ Pers. } & Araçá & & 9 & $\mathrm{CN}$ & $\mathrm{CN} 2 \mathrm{a}$ & Boa \\
\hline & & & 9 & $\mathrm{~T}$ & T1a & Média \\
\hline Myrtaceae/Psidium sp. & Araçá-manso & $\mathrm{N}$ & 1 & $\mathrm{C}$ & $\mathrm{C} 2$ & Média \\
\hline \multirow{2}{*}{$\begin{array}{l}\text { Nyctaginaceae/Guapira } \\
\text { opposita (Vell.) Reitz }\end{array}$} & João-mole & $\mathrm{N}$ & 5 & $\mathrm{C}$ & $\mathrm{C} 2$ & Ruim \\
\hline & & & 4 & $\mathrm{CN}$ & CN1a, CN1b, CN1f, CN1g & Média \\
\hline \multirow[t]{2}{*}{ Nyctaginaceae/Guapira sp. 1} & Bandola- & $\mathrm{N}$ & 9 & $\mathrm{C}$ & $\mathrm{C} 2$ & Média \\
\hline & vermelha & & 3 & $\mathrm{CN}$ & CN1h & Média \\
\hline Nyctaginaceae/Guapira sp.2 & $\begin{array}{l}\text { Bandola- } \\
\text { branca }\end{array}$ & $\mathrm{N}$ & 1 & $\mathrm{C}$ & $\mathrm{C} 2$ & Média \\
\hline \multirow{2}{*}{$\begin{array}{l}\text { Polygonaceae/Coccoloba } \\
\text { laevis Casar. }\end{array}$} & Coité & $\mathrm{N}$ & 1 & $\mathrm{C}$ & $\mathrm{C} 1$ & Média \\
\hline & & & 3 & $\mathrm{CN}$ & $\mathrm{CN} 2 \mathrm{a}$ & Média \\
\hline $\begin{array}{l}\text { Rhamnaceae/Ziziphus } \\
\text { joazeiro Mart. }\end{array}$ & Juá-de-boi & $\mathrm{N}$ & 9 & $\mathrm{C}$ & $\mathrm{C} 1$ & Média \\
\hline Rhamnaceae/Ziziphus sp. & Juá-de-bode & $\mathrm{N}$ & 2 & $\mathrm{C}$ & $\mathrm{C} 1$ & Boa \\
\hline $\begin{array}{l}\text { Rubiaceae/Genipa americana } \\
\text { L. }\end{array}$ & $\begin{array}{l}\text { Jenipapeiro/ } \\
\text { Jenipapo }\end{array}$ & $\mathrm{N}$ & 2 & $\mathrm{C}$ & $\mathrm{C} 2$ & Boa \\
\hline \multirow[t]{2}{*}{ Rubiaceae/Guettarda sp. } & Angélica & $\mathrm{N}$ & 1 & $\mathrm{C}$ & $\mathrm{C} 2$ & Boa \\
\hline & & & 2 & $\mathrm{CN}$ & $\mathrm{CN} 1 \mathrm{~b}, \mathrm{CN} 1 \mathrm{c}$ & Média \\
\hline \multirow{3}{*}{$\begin{array}{l}\text { Rubiaceae/Tocoyena bullata } \\
\text { (Vell.) Mart. }\end{array}$} & Jenipapinho & $\mathrm{N}$ & 2 & $\mathrm{C}$ & $\mathrm{C} 2$ & Ruim \\
\hline & & & 2 & $\mathrm{CN}$ & CN1d, CN1e & Ruim \\
\hline & & & 1 & $\mathrm{~T}$ & T4d & Média \\
\hline $\begin{array}{l}\text { Rutaceae/Citrus reticulata } \\
\text { Blanco }\end{array}$ & Tangerina & $\mathrm{E}$ & 2 & $\mathrm{C}$ & $\mathrm{C} 2$ & Média \\
\hline \multirow{2}{*}{$\begin{array}{l}\text { Rutaceae/Citrus sp. } \\
\text { Salicaceae /Casearia sp. }\end{array}$} & Laranja & $\mathrm{E}$ & 4 & $\mathrm{~T}$ & $\mathrm{~T} 4 \mathrm{~g}$ & Média \\
\hline & Pau-de-espeto & $\mathrm{N}$ & 1 & $\mathrm{C}$ & $\mathrm{C} 1, \mathrm{C} 2$ & Boa \\
\hline \multirow{3}{*}{$\begin{array}{l}\text { Salicaceae/Casearia } \\
\text { grandiflora Cambess. }\end{array}$} & Sapucaia & $\mathrm{N}$ & 4 & $\mathrm{C}$ & $\mathrm{C} 1$ & Boa \\
\hline & & & 10 & $\mathrm{CN}$ & CN1f & Boa \\
\hline & & & 14 & $\mathrm{CN}$ & $\mathrm{CN} 2 \mathrm{a}, \mathrm{CN} 2 \mathrm{~b}, \mathrm{CN} 2 \mathrm{c}$ & Boa \\
\hline \multirow{3}{*}{$\begin{array}{l}\text { Salicaceae/Casearia silvestris } \\
\text { Sw. }\end{array}$} & Camarão & $\mathrm{N}$ & 2 & $\mathrm{C}$ & $\mathrm{C} 1, \mathrm{C} 2$ & Média \\
\hline & & & 2 & $\mathrm{CN}$ & $\mathrm{CN} 2 \mathrm{a}, \mathrm{CN} 2 \mathrm{c}$ & Boa \\
\hline & & & 2 & $\mathrm{O}$ & $\mathrm{O} 2$ & - \\
\hline
\end{tabular}

Sitientibus série Ciências Biológicas 11(2): 239-253. 2011. 


\begin{tabular}{|c|c|c|c|c|c|c|}
\hline $\begin{array}{l}\text { Sapindaceae/Cupania } \\
\text { revoluta } \text { Rolfe }\end{array}$ & $\begin{array}{l}\text { Cambotá- } \\
\text { vermelho }\end{array}$ & $\mathrm{N}$ & $\begin{array}{c}13 \\
5 \\
3 \\
2\end{array}$ & $\begin{array}{l}\mathrm{C} \\
\mathrm{T} \\
\mathrm{T} \\
\mathrm{O}\end{array}$ & $\begin{array}{l}\text { C1 } \\
\text { T4e } \\
\text { T1g } \\
\text { O1 }\end{array}$ & $\begin{array}{l}\text { Média } \\
\text { Boa } \\
\text { Média } \\
\text { Boa }\end{array}$ \\
\hline Sapindaceae/Matayba sp. & $\begin{array}{l}\text { Cambotá- } \\
\text { branco }\end{array}$ & $\mathrm{N}$ & 1 & $\mathrm{C}$ & $\mathrm{C} 2$ & Ruim \\
\hline Sapindaceae/Talisia sp. & $\begin{array}{l}\text { Pitomba-de- } \\
\text { casco }\end{array}$ & $\mathrm{N}$ & 2 & $\mathrm{C}$ & $\mathrm{C} 1$ & Boa \\
\hline $\begin{array}{l}\text { Sapotaceae/Manilkara } \\
\text { salzmannii (A.DC.) H.J. Lam }\end{array}$ & Maçaranduba & $\mathrm{N}$ & $\begin{array}{c}6 \\
12 \\
7 \\
7\end{array}$ & $\begin{array}{l}\mathrm{C} \\
\mathrm{CN} \\
\mathrm{CN} \\
\mathrm{T}\end{array}$ & $\begin{array}{c}\mathrm{C} 2 \\
\mathrm{CN} 1 \mathrm{~b}, \mathrm{CN} 1 \mathrm{c}, \mathrm{CN} 1 \mathrm{f} \\
\mathrm{CN} 2 \mathrm{~b}, \mathrm{CN} 2 \mathrm{c} \\
\text { T1e }\end{array}$ & $\begin{array}{c}\text { Média } \\
\text { Muito boa } \\
\text { Muito boa } \\
\text { Boa }\end{array}$ \\
\hline Sapotaceae/Manilkara sp. & Mirinduba & $\mathrm{N}$ & $\begin{array}{l}2 \\
4 \\
3\end{array}$ & $\begin{array}{c}\mathrm{C} \\
\mathrm{T} \\
\mathrm{CN}\end{array}$ & $\begin{array}{c}\mathrm{C} 1 \\
\mathrm{~T} 4 \mathrm{i} \\
\mathrm{CN} 1 \mathrm{a}\end{array}$ & $\begin{array}{c}\text { Boa } \\
\text { Boa } \\
\text { Média }\end{array}$ \\
\hline Sapotaceae/Poutreria sp. & Gameleiro & $\mathrm{N}$ & 5 & $\mathrm{C}$ & $\mathrm{C} 2$ & Ruim \\
\hline $\begin{array}{l}\text { Caesalpiniaceae /Dialium } \\
\text { guianense (Aubl.) Sandw. }\end{array}$ & $\begin{array}{l}\text { Tapiroroca/ } \\
\text { Pororoca }\end{array}$ & $\mathrm{N}$ & 3 & $\mathrm{CN}$ & $\begin{array}{l}\text { CN1b, CN1c, CN1f, } \\
\text { CN1d }\end{array}$ & $\begin{array}{l}\text { Boa } \\
\text { Média }\end{array}$ \\
\hline $\begin{array}{l}\text { Solanaceae/Solanum } \\
\text { paludosum Moric. }\end{array}$ & Jurubeba & $\mathrm{N}$ & 5 & $\mathrm{C}$ & $\mathrm{C} 2$ & Ruim \\
\hline $\begin{array}{l}\text { Vochysiaceae/ Cecropia } \\
\text { pachystachya Trécul }\end{array}$ & $\begin{array}{l}\text { Embaúba/ } \\
\text { Umbaúba }\end{array}$ & $\mathrm{N}$ & $\begin{array}{c}18 \\
6 \\
1\end{array}$ & $\begin{array}{l}\mathrm{C} \\
\mathrm{T} \\
\mathrm{T}\end{array}$ & $\begin{array}{l}\mathrm{C} 2 \\
\mathrm{~T} 3 \mathrm{c} \\
\mathrm{T} 1 \mathrm{e}\end{array}$ & $\begin{array}{c}\text { Ruim } \\
\text { Boa } \\
\text { Boa }\end{array}$ \\
\hline $\begin{array}{l}\text { Vochysiaceae/ Vochysia } \\
\text { lucida Klotzsch ex } \\
\text { M.R.Schomb. }\end{array}$ & Mangue-doce & $\mathrm{N}$ & $\begin{array}{l}3 \\
5\end{array}$ & $\begin{array}{c}\mathrm{C} \\
\mathrm{CN}\end{array}$ & $\begin{array}{c}\mathrm{C} 1 \\
\mathrm{CN} 1 \mathrm{~b}, \mathrm{CN} 1 \mathrm{c}, \mathrm{CN} 1 \mathrm{f}\end{array}$ & $\begin{array}{c}\text { Média } \\
\text { Boa }\end{array}$ \\
\hline
\end{tabular}

